\title{
Protein kinase C mediated internalization of ErbB2 is independent of clathrin, ubiquitination and Hsp90 dissociation
}

\section{Markus Dietrich ${ }^{1,2}$, Muhammad Salman Malik ${ }^{1,3}$, Filip Nikolaysen $^{1}$, Marianne Skeie ${ }^{2}$, and Espen Stang ${ }^{1, *}$}

${ }^{1}$ Department of Pathology, Oslo University Hospital, Oslo, Norway

${ }^{2}$ Institute of Clinical Medicine, University of Oslo, Oslo, Norway

${ }^{3}$ Current address: Department of Food Safety and Infection Biology,

Norwegian University of Life Sciences, Oslo, Norway

*Corresponding author: Espen Stang, Department of Pathology, Oslo University Hospital, Post box 4950 Nydalen, 0424 Oslo, Norway.

Tel: 47-23071483. E-mail: espsta@ @r-research.no

Abbreviations: CHX, cycloheximide; EEA1, early endosome antigen 1; GA, geldanamycin; LAMP1, lysosomal-associated membrane protein 1; PMA, phorbol 12-myristate 13-acetate; RTK, receptor tyrosine kinase 


\begin{abstract}
Overexpression of ErbB2 is frequent in cancer and understanding the mechanisms which regulate its expression is important. ErbB2 is considered endocytosis resistant. It has no identified ligand, but upon heterodimerization it is a potent mediator of proliferative signaling. A recent study established a role for protein kinase $\mathrm{C}(\mathrm{PKC})$ in internalization and recycling of ErbB2. We have now further investigated the molecular mechanisms involved in PKC-mediated downregulation of ErbB2. We confirm that PMA-induced PKC activation causes ErbB2 internalization, but while the Hsp90 inhibitor 17-AAG induced ErbB2 degradation, PMA had no such effect. When combined with 17-AAG, PMA had additive effect on ErbB2 internalization indicating that Hsp90 inhibition and PKC activation induce internalization by alternative mechanisms. We confirm that while 17-AAG-induced internalization was clathrin-mediated, PMA-induced internalization was clathrin independent. This difference may be explained by while both 17-AAG and PMA reduced the constitutive tyrosine phosphorylation of ErbB2, only 17-AAG induced Hsp90 dissociation, Hsp70 recruitment and ubiquitination of ErbB2. Importantly, since PMA induced internalization of ErbB2, but not dissociation of Hsp90, Hsp90 does not per se retain ErbB2 at the plasma membrane. The morphology of the compartment into which receptors are sorted upon PKC activation has not previously been identified. By immuno-electron microscopy, we show that PMA sorts ErbB2 into a complex tubulovesicular or cisternal organelle resembling a previously described endocytic recycling compartment.
\end{abstract}

Keywords: ErbB2; protein kinase C (PKC); endocytosis; endosomal sorting; Hsp90 


\section{INTRODUCTION}

ErbB2 (HER2/neu), which belongs to the epidermal growth factor receptor (EGFR) family of receptor tyrosine kinases, differs from the other family members in several ways. ErbB2 has no known ligand, but despite this, its extracellular region adopts an open confirmation with the dimerization arm constitutively exposed (Garrett, McKern et al. 2003). This makes ErbB2 primed for dimerization and ErbB2 is the preferred heterodimerization partner for other members of the EGFR family (Graus-Porta, Beerli et al. 1997). Importantly, several studies show that ErbB2 is endocytosis resistant, be it as monomer, homodimer or heterodimer, and, if internalized, it is efficiently recycled back to the plasma membrane (Baulida, Kraus et al. 1996, Austin, De Maziere et al. 2004, Hommelgaard, Lerdrup et al. 2004). The exact reason(s) for the endocytosis resistance is (are) still unclear. Several explanations have been reported, among which are lack of internalization signal(s), active retention through interaction with other plasma membrane constituents and/or inhibited formation of clathrin coated pits (for reviews see Roepstorff, Grovdal et al. 2008, Sorkin and Goh 2009, Bertelsen and Stang 2014).

ErbB2 is an Hsp90 client, and Hsp90 inhibitors, like geldanamycin (GA) and 17-AAG, induce internalization and degradation of ErbB2. The molecular mechanisms are, however, not fully resolved. Upon Hsp90 inhibition, Hsp90 is replaced by Hsp70, ubiquitin ligases like CHIP (Xu, Marcu et al. 2002, Zhou, Fernandes et al. 2003) and/or CUL5 (Ehrlich, Wang et al. 2009) are recruited, and ErbB2 is endocytosed by clathrin-mediated endocytosis (Pedersen, Madshus et al. 2008). ErbB2 does in itself not bind to the clathrin coated pit localized adaptor complex AP-2 (Baulida, Kraus et al. 1996), but ubiquitination might serve as an endocytosis signal (Pedersen, Madshus et al. 2008, Vuong, Berger et al. 2013). It has also been shown that inhibition of Hsp90 can induce cleavages within the cytoplasmic tail of ErbB2 and that this leads to its internalization (Tikhomirov and Carpenter 2000, Lerdrup, Bruun et al. 2007). Cleavages might expose otherwise hidden internalization signals. Alternatively, the results can indicate that full-length ErbB2 is actively retained at the plasma membrane. In support of the latter, studies have shown that the ErbB2-Hsp90 complex interacts with plasma membrane localized proteins such as the flotillins (Pust, Klokk et al. 2013), members of the ERM protein family (Asp, Kvalvaag et al. 2016), the plasma membrane calcium ATPase2 (PMCA2) (Jeong, VanHouten et al. 2016, Jeong, Kim et al. 2017), and the scaffolding sodium-hydrogen exchanger regulatory factor 1 (NHERF1) (Jeong, VanHouten et al. 2017). Inhibition of these interactions can cause Hsp90 dissociation, c-Cbl mediated ubiquitination and internalization of ErbB2 (Pust, Klokk et al. 2013, Asp, Kvalvaag et al. 2016, Jeong, Kim et al. 2017, Jeong, VanHouten et al. 2017). However, since ErbB2 mutants that do not bind Hsp90 are stable (Tikhomirov and Carpenter 2003, Xu, Yuan et al. 2005), it is unlikely that the retention directly depends on Hsp90. Likewise, it has been reported that Hsp90 dissociates from ErbB2 upon heterodimerization (Citri, Gan et al. 2004), but ErbB2 still prevents internalization of EGFR-ErbB2 and ErbB2-ErbB3 heterodimers (Haslekas, Breen et al. 2005, Hughes, Berger et al. 2009, Sak, Szymanska et al. 2013). It has thus been suggested that inhibited downregulation of ErbB2 is due to an Hsp90-independent retention, but that $\mathrm{Hsp} 90$ inhibitors induce ErbB2 ubiquitination, which serves as a signal for internalization and degradation (Bertelsen and Stang 2014).

The plasma membrane expression of ErbB2 can also be regulated by members of the protein kinase C (PKC) family (Ouyang, Gulliford et al. 1998, Bailey, Luan et al. 2014). The PKCs are serine- and/or threonine kinases involved in numerous cellular processes and various human diseases (reviewed in Mochly-Rosen, Das et al. 2012). The family consists of 
conventional (classical) PKCs which require diacylglycerol (DAG), calcium ions $\left(\mathrm{Ca}^{2+}\right)$ and phospholipids for activation, novel PKCs which need DAG, but not $\mathrm{Ca}^{2+}$, and atypical PKCs which require neither DAG, nor $\mathrm{Ca}^{2+}$ but phosphatidylserine for full activation. The tumor promoting phorbol ester, phorbol 12-myristate 13-acetate (PMA, also known as TPA), can mimic DAG and is a potent activator of conventional and novel PKCs. Several previous studies have shown that PKCs can regulate expression and localization of the EGFR. Upon PKC activation, EGFR gets phosphorylated on threonine 654 (Thr-654) and downregulated from the plasma membrane. Instead of being routed to lysosomes for degradation, it is sequestered in a modified endosomal compartment (Bao, Alroy et al. 2000, Llado, Timpson et al. 2008, Liu, Idkowiak-Baldys et al. 2013). As for Thr-654 in EGFR, phorbol ester-induced activation of PKCs induces phosphorylation of Thr-686 in ErbB2 (Ouyang, Gulliford et al. 1998), and while PKC inhibitors were found to reduce 17-AAG-induced downregulation of ErbB2, PKC activation caused downregulation of ErbB2 from the plasma membrane. Contrary to 17-AAG, activation of PKC did not induce ErbB2 degradation. Instead of being degraded, ErbB2 was stabilized in specialized endosomes (Bailey, Luan et al. 2014). Although PKC inhibitors were found to reduce the effect of 17-AAG, the effect of PKCs on ErbB2-Hsp90 interaction has, to our knowledge, not been investigated. Neither has it been shown whether PKCs have effects on ErbB2 ubiquitination.

Internalization of plasma membrane constituents can occur by several different pathways. GA-induced internalization of ErbB2 has been shown to depend on clathrin-mediated internalization (Pedersen, Madshus et al. 2008). EGF-induced internalization of EGFR may, however, depending on EGF concentration and ubiquitination status, be both clathrindependent and -independent (Sigismund, Algisi et al. 2013, Fortian, Dionne et al. 2015). Little is known about how receptors are internalized upon PKC activation. PKC-induced sequestration of certain plasma membrane molecules was reported to depend on clathrinmediated endocytosis. However, also molecules internalized by clathrin-independent internalization got sequestered (Idkowiak-Baldys, Becker et al. 2006), but the inhibitors used, hypertonic sucrose or potassium depletion, are probably not specific (Vercauteren, Vandenbroucke et al. 2010). The internalization pathway(s) thus remain(s) to be identified. Relatively little is known about the compartment into which the receptors are sequestered. The compartment is often referred to as the pericentrion, and based on being positive for, among others, Rab 11, it most likely represents a specialized endocytic recycling compartment (ERC) (reviewed in Alvi, Idkowiak-Baldys et al. 2007). In line with this, Bailey et al. showed that ErbB2 was sequestered in an Arf6 positive compartment upon PKC activation (Bailey, Luan et al. 2014). Several studies indicate that the PKCs regulate the dynamics and localization of signal transduction (reviewed in Rosse, Linch et al. 2010), and the data of Bailey et al. suggest that the pericentrion serves as a hub for ErbB2-mediated signaling (Bailey, Luan et al. 2014). However, nothing is to our knowledge known about the morphology of the pericentrion. Upon GA-induced internalization, ErbB2 is translocated to internal vesicles of multivesicular bodies (MVBs) (Pedersen, Madshus et al. 2008) from which signaling is highly unlikely. Morphological studies and localization of proteins within the pericentrion are thus important.

We have now further investigated how PKC activators and inhibitors affect ErbB2. In line with previous studies, we find that PMA-induced activation of PKC downregulates ErbB2 from the plasma membrane without causing ErbB2 degradation. We find that PKC activation has no effect on ErbB2-Hsp90 interaction, demonstrating that Hsp90 does not per se retain ErbB2 at the plasma membrane. PKC activation did not induce ubiquitination of ErbB2 and contrary to 17-AAG, PMA induced clathrin-independent internalization of ErbB2. Depletion 
of cholesterol did, however, inhibit the internalization suggesting a role of lipid rafts in PKC regulated trafficking of ErbB2. Furthermore, we morphologically characterized the compartment into which ErbB2 is sequestered. Immuno-electron microscopy (immuno-EM) showed that ErbB2 was concentrated in a complex tubulovesicular or cisternal compartment resembling previously described ERCs.

\section{MATERIALS AND METHODS}

\section{Reagents and Antibodies}

Mouse anti-ErbB2 extracellular domain (TAB250), rabbit anti-ErbB2 intracellular domain (PAD:Z4881), Alexa Fluor 555-conjugated donkey anti-mouse IgG, and Alexa Fluor 647conjugated donkey anti-goat IgG antibodies were from Thermo Fisher Scientific (Waltham, MA, USA). Mouse anti-ubiquitin, mouse anti-phosphotyrosine, rabbit anti-Hsp90, mouse anti-Hsp70 and goat anti-early endosome antigen 1 (EEA1) (N-19) antibodies were from Santa Cruz Biotechnology (Santa Cruz, CA, USA). Rabbit anti-ErbB2 (29D8) was from Cell Signaling Technology (Danvers, MA, USA). Herceptin (trastuzumab) was from Roche Pharma (Grenzach-Wyhlen, Germany). Rabbit anti- $\beta$-tubulin, rabbit anti-LAMP1 and rabbit anti-PKC $\alpha$ antibodies were from Abcam (Cambridge, UK). Mouse-anti ErbB2 (42) and mouse anti-PKC $\delta$ antibodies were from BD Biosciences (San Jose, CA, USA). Alexa488conjugated mouse anti-ErbB2 (24D2) antibody was from BioLegend (San Diego, CA, USA). Peroxidase-conjugated donkey anti-rabbit and anti-mouse IgG, as well as Alexa Fluor 488conjugated donkey anti-human and anti-rabbit IgG antibodies were from Jackson ImmunoResearch Laboratories (West Grove, PA, USA). Rabbit anti-mouse IgG antibody was from Cappel Research Reagents (ICN Biochemicals, Irvin, CA). Ro 31-8220 was from Merck Millipore (Darmstadt, Germany). 17-AAG was from TOCRIS (Bio-Techne, Abingdon, UK). Unless specifically noted, all other materials and chemicals were from Sigma-Aldrich (St. Louis, MO, USA).

\section{Cell Culture and Treatment}

SK-BR-3 cells were grown in DMEM with Ultraglutamine I and $4.5 \mathrm{~g} / \mathrm{l}$ Glucose (Lonza, Basel, Switzerland). A mixture of 50 units of Potassium Penicillin and $50 \mu \mathrm{g}$ of Streptomycin Sulfate per $1 \mathrm{ml}$ of DMEM and $15 \%(\mathrm{v} / \mathrm{v})$ fetal bovine serum were routinely used. PAE.ErbB2 cells (Pedersen, Breen et al. 2009) were grown in Ham's F12 (Lonza) with 10\% (v/v) fetal bovine serum, a mixture of 50 units of Potassium Penicillin and $50 \mu \mathrm{g}$ of Streptomycin Sulfate, as well as $30 \mu \mathrm{g}$ Zeocin (Thermo Fisher Scientific) per $1 \mathrm{ml}$ of Ham's F12. 17-AAG, PMA and Ro 31-8220 were dissolved in DMSO and therefore DMSO was used as vehicle control in all experiments where PMA, 17-AAG or Ro 31-8220 was present.

siRNA Transfection of cells

For knock-down experiments, cells were reversely transfected with short interfering RNA (siRNA) twice with a 48 hours interval using Lipofectamine ${ }^{\circledR}$ RNAiMax (Thermo Fisher Scientific). Cells were used for experiments 48 hours after the second transfection. The transfection was performed according to the manufacturer's protocol using a final concentration of $50 \mathrm{nM}$ siRNA. For knock-down of clathrin heavy chain, the siRNA duplex to the target sequence GCAAUGAGCUGUUUGAAGA (Huang, Khvorova et al. 2004) was synthesized and annealed by Thermo Fisher Scientific. On-TARGETplus Non-targeting siRNA \#2 (D-001810-02) was from Dharmacon (Horizon Discovery, Cambridge, UK). 


\section{Immunoblotting}

Cells were lysed in SDS (sodium-dodecyl sulfate) lysis buffer (Szymanska, Fosdahl et al. 2016) containing $10 \mu \mathrm{g} / \mathrm{ml}$ 4-(2-Aminoethyl)benzenesulfonyl fluoride hydrochloride (AEBSF). Lysates were subjected to homogenization using a QIAshredder column (QIAGEN, Valencia, CA, USA). Sample buffer (Szymanska, Fosdahl et al. 2016) was added to the lysates before incubation for $10 \mathrm{~min}$ at $95^{\circ} \mathrm{C}$. Proteins were separated by SDS-gel electrophoresis using 10\% Mini-PROTEAN®TGXTM Precast Gels from Bio-Rad Laboratories (Hercules, CA, USA). Afterwards, proteins were blotted onto a nitrocellulose membrane using Trans-Blot ${ }^{\circledR}$ TurboTM Transfer System (Bio-Rad Laboratories). The membranes were incubated with 5\% Blotting-Grade Blocker in TBS-Tween 20 (Bio-Rad Laboratories) before incubation with primary and secondary antibodies diluted in $1 \%$ Blotting-Grade Blocker in TBS-Tween 20 for 2 hours at room temperature or over night at $4^{\circ}$ C. For detection of proteins, Super Signal West Dura Extended Duration Substrate from Thermo Fisher Scientific was used. Visualization was achieved with the ChemiDoc MP System (Bio-Rad Laboratories). Image Lab Software version 4.0.1 build 6 (Bio-Rad Laboratories) and Adobe Photoshop (Adobe Systems, San José, CA, USA) were used for image processing.

\section{Immunoprecipitation and co-immunoprecipitation}

To study ubiquitination and phosphorylation of ErbB2, cells were lysed in preheated $\left(100^{\circ} \mathrm{C}\right)$ $1 \%$ SDS in PBS, incubated at $100^{\circ} \mathrm{C}$ for $5 \mathrm{~min}$ and homogenized using a QIA-shredder column (QIAGEN). The lysates were added to protein A-coupled magnetic beads $(2.8 \mu \mathrm{M})$ (Thermo Fisher Scientific) precoupled to rabbit anti-ErbB2 (PAD:Z4881) antibody in 0.1M phosphate buffer, $\mathrm{pH}=8$, with $0.05 \%$ Triton $\mathrm{X}-100$ at room temperature for 1 hour. The beads were resuspended in $2 \mathrm{x}$ immunoprecipitation (IP) buffer (2\% (v/v) Triton X-100, $0.5 \%$ (w/v) sodium deoxycholate, $1 \%(\mathrm{w} / \mathrm{v})$ bovine serum albumin, $2 \mathrm{mM}$ EDTA, $40 \mathrm{mM} \mathrm{NaF}, 6$ $\mathrm{mM}$ NEM, 1:100 (v/v) protease inhibitor and phosphatase inhibitor cocktails (P8340 and P5726)). Antibody-coupled magnetic beads and cell lysates were gently mixed for 1 hour at $4^{\circ} \mathrm{C}$. The beads were then washed four times with $1 \mathrm{x}$ IP buffer (50\% 2x IP buffer $+50 \%$ SDS [1\%] in PBS), once in 1:10 diluted PBS and then eluted in 2x sample buffer $(20 \mathrm{mM}$ Tris- $\mathrm{HCl}$ pH 6.8, $10 \mathrm{mM}$ EDTA, $100 \mathrm{mM} \mathrm{NaF}, 60 \mathrm{mM}$ sodium pyrophosphate, 4\% SDS, $2 \% \beta$ Mercaptoethanol, 20\% Glycerol, $0.006 \%$ Bromophenol Blue) at $95^{\circ} \mathrm{C}$ for $5 \mathrm{~min}$. Immunoprecipitated ErbB2 was analyzed by immunoblotting with antibodies to ErbB2, phosphotyrosine and ubiquitin.

For co-immunoprecipitation analysis, cells were washed three times in ice-cold PBS and lysed for $30 \mathrm{~min}$ on ice in lysis buffer (20 mM HEPES pH 7.2, 0.1\% Triton X-100, $2 \mathrm{mM}$ $\mathrm{MgCl} 2,100 \mathrm{mM} \mathrm{NaCl}, 0.1 \mathrm{mM}$ EDTA supplemented with 1:100 protease and phosphatase inhibitor cocktails (P8340 and P5726), $60 \mathrm{mM}$ Octyl $\beta$-D-glucopyranoside and $20 \mathrm{mM}$ NEM (N-Ethylmaleimide)). The protein G-coupled magnetic beads $(2.8 \mu \mathrm{M})$ (Thermo Fisher Scientific) were precoupled to rabbit anti-ErbB2 antibody. Preparation of the beads and all the washing steps were done as described above. Proteins were eluted from the beads in $2 \mathrm{x}$ sample buffer. For detection of co-immunoprecipitation eluted samples were blotted with antibodies to ErbB2, Hsp70 and Hsp90.

\section{Flow Cytometry}

Cells were seeded one day prior to experiments in 6-well plates. Following treatment, cells were rinsed $3 \mathrm{x}$ with PBS and detached with trypsin/EDTA. Trypsinization was stopped by 
addition of trypsin inhibitor. Cell suspensions were transferred to 96-well plates and washed $2 \mathrm{x}$ with PBS. Cells were stained $30 \mathrm{~min}$ on ice with Fixable Viability Dye eFluor 450 (eBioscience, San Diego, CA, USA) for dead-live discrimination and afterwards washed $2 \mathrm{x}$ with FACS buffer ( $0.5 \%$ fetal bovine serum/0.1\% EDTA pH $=8$ in PBS). Cells were fixed at room temperature in 4\% PFA for $10 \mathrm{~min}$. For staining of plasma membrane localized ErbB2, cells were incubated for $30 \mathrm{~min}$ on ice with Alexa488-conjugated anti-ErbB2 antibody and washed $2 x$ with FACS buffer. Stained cells were run using a LSR II flow cytometer from BD Biosciences (San Jose, CA, USA). Results were analyzed with FlowJo software version 10.1 (FlowJo, Ashland, OR, USA) and graphically displayed with GraphPad Prism 6 (GraphPad Software, La Jolla, CA, USA).

\section{ErbB2 internalization assay and staining of cells}

To verify ErbB2 internalization, cells were incubated with the humanized monoclonal antiErbB2 antibody Herceptin in MEM with $0.1 \%$ bovine serum albumin (BSA) for $30 \mathrm{~min}$ on ice. The cells were then chased in Herceptin-free medium (MEM+0.1\% BSA) for 4 hours at $37^{\circ} \mathrm{C}$ before fixation in $4 \%$ PFA for $10 \mathrm{~min}$. After quenching with $50 \mathrm{mM} \mathrm{NH} \mathrm{NH}_{4} \mathrm{Cl}$ and permeabilization with $0.01 \%$ Triton X-100, internalized Herceptin was detected using an Alexa Fluor 488-conjugated anti-human $\operatorname{IgG}$ antibody. To localize ErbB2, fixed and permeabilized cells were stained with an anti-ErbB2 extracellular domain (TAB250) antibody, followed by an Alexa Fluor 555-conjugated anti-mouse IgG antibody. EEA1 antibodies were detected with an Alexa Fluor 647-conjugated anti-goat antibody and LAMP1 antibodies were detected with an Alexa Fluor 488-conjugated anti-rabbit antibody.

\section{Imaging and Image Analysis}

Laser scanning confocal microscopy was done on an Olympus Fluoview 1000 (BX61W1) system with 405, 488, 543 and 633nm laser lines and an UPlanSApo 60x oil objective with a numerical aperture of 1.35 (Olympus, Hamburg, Germany). Images were acquired with the FV10-ASW-v.42 software and montages were assembled in ImageJ (Version2.0.0rc41/1.50d; Java 1.6.0_24 [64-bit]) from National Institutes of Health, USA.

\section{Immuno-electron microscopy}

Cells were fixed with $4 \%$ methanol-free paraformaldehyde and $0.1 \%$ glutaraldehyde (Electron Microscopy Sciences, Hatfield, PA) in 0.2 M HEPES and prepared for cryo immuno-electron microscopy basically as described in (Griffiths, McDowall et al. 1984). Labeling for ErbB2 was done using mouse anti-ErbB2 (TAB250) followed by rabbit anti-mouse IgG. Bound antibodies were visualized using colloidal gold coated with protein A (G. Posthuma, Utrecht, The Netherlands). Sections were examined using a Tecnai $G^{2}$ Spirit TEM (FEI, Eindhoven, The Netherlands) equipped with a Morada digital camera using iTEM (SIS) software (Olympus Soft Imaging Solutions, Münster, Germany). Images were processed using Adobe Photoshop. To quantify labeling the total number of intracellular gold particles on a minimum of 25 cell profiles was counted and grouped with respect to organelle localization. For each condition, three parallel labeling experiments were included and the results are presented as mean \pm SD. Non-specific labeling, as judged by labeling on mitochondria, was not included in the presented results, but when counted it was found to be minimal (about 1\% of total labeling).

\section{Statistical Data Analysis}


Statistical analysis was performed using GraphPad Prism 6. Data analyzed were the results of at least three independent experiments. Mean \pm SD was calculated and statistical significance was determined by using one unpaired $t$ test per row. Significance is denoted as n.s., nonsignificant; *, $\mathrm{P}<0.05 ; * *, \mathrm{P}<0.01$; ***, $\mathrm{P}<0.001$.

\section{RESULTS AND DISCUSSION}

Both 17-AAG and PMA downregulate ErbB2 from the plasma membrane, but only 17-AAG induces ErbB2 degradation

It has previously been shown that both Hsp90 inhibition and PKC activation independently downregulate ErbB2 from the plasma membrane. To further investigate this, cells were preincubated with cycloheximide (CHX) to inhibit protein synthesis and ensure that the induced effects are not counteracted by upregulated protein synthesis. Flow cytometry confirmed the reported downregulation and we could furthermore identify an additive effect when 17-AAG and PMA were combined (Figure 1A). A previous study also identified an increased downregulation when PMA and 17-AAG were combined (Bailey, Luan et al. 2014), but the effect was then not directly additive. A likely explanation for the difference is the use of different concentrations of 17-AAG $(25 \mathrm{nM}$ vs. $3 \mu \mathrm{M})$. Since we used a 17-AAG concentration that can be expected to have maximal effect (Bailey, Luan et al. 2014), the added effect of PMA suggests that different mechanisms drive 17-AAG- and PMA-induced downregulation of ErbB2.

We also investigated the effects of 17-AAG and PMA on degradation of ErbB2. The samples were analyzed by immunoblotting for both the intracellular and the extracellular domain of ErbB2. This was done since Hsp90 inhibition has been reported to induce internalization of both full length ErbB2 (Lerdrup, Hommelgaard et al. 2006, Pedersen, Madshus et al. 2008), and intracellular cleaved ErbB2 (Tikhomirov and Carpenter 2000, Lerdrup, Bruun et al. 2007). As shown in Figure 1B-D, 17-AAG, but not PMA, induced a measurable degradation of ErbB2. Quantification showed similar effects when blotting for the extracellular and intracellular domain. When examining the gel, no low molecular weight bands, representing ErbB2 cleavage, were observed (data not shown). This supports our previous studies which concluded that ErbB2 was internalized and degraded as a full length receptor. Although treatment with PMA alone did not induce ErbB2 degradation, the combinatorial treatment again showed an increased effect and caused the strongest degradation. This could be due to the increased internalization of ErbB2 when 17-AAG and PMA were combined and, as discussed below, effects of 17-AAG on ubiquitination and degradation of ErbB2. Blotting for $\mathrm{PKC} \alpha$, a classical $\mathrm{PKC}$, and $\mathrm{PKC} \delta$, a novel $\mathrm{PKC}$, were included to confirm PMA-induced $\mathrm{PKC}$ activation and subsequent degradation (see Figure 1B).

\section{PKC inhibition reverses effects of PMA, but not of 17-AAG}

Based on the observed effects of PMA and/or 17-AAG we next tested how PKC inhibition affected ErbB2 expression. As especially PKC $\alpha$ has been implicated in the regulation of EGFR (Wang, Yan et al. 2007), and SK-BR-3 cells have very low levels of PKC $\beta$ and PKC $\gamma$ (Le, Marcelli et al. 2001), we used the PKC inhibitor Ro 31-8220 which mainly inhibits classical PKCs. While the PKC inhibitor alone did not show any significant effect on plasma membrane expression of ErbB2, it clearly reversed the PMA-induced downregulation of ErbB2 (Figure 2A). It has previously been reported that Ro 31-8220 also mildly inhibits the 
effect of 17-AAG (Bailey, Luan et al. 2014). However, we did not observe any inhibitory effect of Ro 31-8220 on 17-AAG-induced downregulation of ErbB2. As discussed above, this is probably due to the use of different $17-\mathrm{AAG}$ concentrations.

When examining the degradation of ErbB2 there were no obvious effects of Ro 31-8220 alone or in combination with PMA (Figure 2B-C). Nor did Ro 31-8220 have effect on 17AAG induced ErbB2 degradation (data not shown). This shows that PKC inhibition effectively inhibits PMA-induced ErbB2 downregulation, supporting that PKCs can regulate internalization of ErbB2. Furthermore, it also shows that 17-AAG-induced internalization and degradation is, at least at high 17-AAG concentrations, not dependent on a basal PKC activity.

\section{ErbB2 is internalized to complex tubulovesicular compartments upon PKC activation}

To verify that PKC activation caused internalization of ErbB2, and determine its intracellular localization and sorting, we initially carried out an antibody-based internalization assay. Cells were incubated with the anti-ErbB2 antibody Herceptin on ice for $30 \mathrm{~min}$, before wash and chase for $4 \mathrm{~h}$ at $37^{\circ} \mathrm{C}$. It is discussed whether Herceptin alone can induce internalization of ErbB2, but in line with previous studies (Hommelgaard, Lerdrup et al. 2004, Longva, Pedersen et al. 2005), we found no internalization of Herceptin in cells treated with DMSO only. Internalization could, however, clearly be seen in cells treated with 17-AAG, and although to a lesser extent, also in PMA-treated cells (Figure 3). After 17-AAG treatment, internalized Herceptin was found in both early endosome antigen 1 (EEA1) (Figure 3A) and lysosomal-associated membrane protein 1 (LAMP1) (Figure 3B) positive compartments. Upon incubation with PMA, Herceptin was found in compartments which were partially positive for EEA1, but negative for LAMP1. It has been previously shown that PMA induces an intracellular accumulation of antibody-ErbB2 complexes in a perinuclear compartment called the pericentrion (Bailey, Luan et al. 2014). Although we were not able to directly reproduce this localization, our results confirm that PKC activation causes internalization of antibody-ErbB2 complexes, and support that it causes sorting to a specialized compartment. Incubation with 17-AAG and PMA in combination caused an efficient internalization. As upon treatment with 17-AAG alone, Herceptin localized to both EEA1 and LAMP1 positive compartments. The size of each compartment was, however, clearly increased (Figure 3).

To determine the intracellular localization of ErbB2 itself in more detail, we initially used immunolabeling combined with confocal laser scanning microscopy (Supplementary Figure 1). In control cells, ErbB2 staining was restricted to the plasma membrane. It should be noted that the cells were not incubated with $\mathrm{CHX}$ and downregulation can thus not be directly compared with the flow or immunoblotting data shown above. Still, in 17-AAG treated cells, the plasma membrane staining for ErbB2 was clearly reduced, while intracellular staining was increased localizing to EEA1 and LAMP1 positive compartments. This confirms previous studies showing that Hsp90 inhibition induces ErbB2 internalization and targets it for lysosomal degradation via the classical degradative pathway (Lerdrup, Hommelgaard et al. 2006, Pedersen, Madshus et al. 2008). The effect of PMA was less obvious, but compared to the control the intracellular labeling was increased, with partial colocalization with EEA1, but no apparent colocalization with LAMP1. The PMA + 17-AAG combination did, however, strongly reduce the plasma membrane staining and ErbB2 was instead localized to large vesicular compartments which were partially positive for EEA1 and LAMP1.

Since the effect of PMA was difficult to judge, we used immuno-EM to compare PMA- and 17-AAG-induced trafficking of ErbB2 in detail. In control cells, ErbB2 was concentrated at the plasma membrane, with only highly limited amounts in early endosome like 
compartments (Figure 4A), MVBs and the Golgi (data not shown). In line with previous studies, incubation with 17-AAG decreased the labeling for ErbB2 at the plasma membrane (data not shown) and strongly increased the labeling on internal vesicles of MVBs (Figure 4B), supporting trafficking to late endosomes and lysosomes for degradation. In cells treated with PMA, the plasma membrane labeling for ErbB2 remained strong. However, compared to control cells, the labeling also appeared more frequently in empty vesicular compartments which morphologically resemble enlarged early endosomes (Figure 4C). These probably correspond to the EEA1 positive compartments observed by confocal microscopy (see Figure 3A). Importantly, we also observed increased labeling for ErbB2 in what on micrographs appeared as small vesicles (Figure 4D) and tubular elements (Figure 4E-F). Since micrographs only show two dimensions within ultrathin sections, the labeling indicates localization of ErbB2 to what in three dimensions probably represent complex tubulovesicular and/or cisternal structures. The morphology is similar to a previously identified ERC (Prekeris, Klumperman et al. 1998), and this supports that PKC activation causes sequestration of ErbB2 in a specialized recycling compartment. Quantification of the intracellular labeling verified the differences (Table 1). While more than $40 \%$ of the labeling in 17-AAG treated cells localized to MVBs, almost 50\% localized to clusters of vesicular and tubular structures in PMA treated cells. Under each condition about $1 / 3$ of the labeling was classified as not characterized. This represents gold particles on single small vesicular structures not associated with clusters of vesicles or tubules, and labeling on areas with no clearly identified morphology. In cells incubated with the PMA + 17-AAG combination, as much as $70 \%$ of the labeling was concentrated in MVBs. These MVBs (Supplementary Figure 2) were often found in groups and tended to be larger and more irregularly shaped compared to MVBs in control cells and cells exposed to 17-AAG only. Likewise the internal vesicles of the MVBs were more irregular in size and shape.

\section{PKC-mediated downregulation is clathrin-independent}

ErbB2 does not bind to AP-2 and is considered to be internalization resistant (Baulida, Kraus et al. 1996). Despite this, GA-mediated inhibition of Hsp90 induces clathrin-dependent internalization of ErbB2 (Pedersen, Madshus et al. 2008). Since the combination of PMA and 17-AAG had additive effect, which could suggest different mechanisms for ErbB2 internalization, we investigated to what extent clathrin-mediated endocytosis is involved. For this we used a PAE cell line (PAE.ErbB2) stably transfected with human ErbB2 as the only ErbB family member. This cell line was chosen since our previous studies show that we get a very efficient knock down of clathrin heavy chain (CHC) in PAE cells (Fosdahl, Dietrich et al. 2017). As shown in Figure 5, 17-AAG-induced downregulation of ErbB2 was efficiently inhibited while the downregulation of ErbB2 after PMA treatment was not influenced. This confirms that internalization of ErbB2 upon Hsp90 inhibition is clathrin-dependent, and importantly, it shows that PKC-mediated internalization occurs in a clathrin-independent manner. When PMA and 17-AAG were combined we observed no effect of CHC knockdown at early time points, indicating that PKC activation is sufficient to drive an efficient clathrinindependent internalization of ErbB2. After prolonged treatment, however, the internalization was clearly reduced in the clathrin knockdown samples. This suggests that when PKC activity is reduced due to the PMA-induced degradation (see Figure 1B), 17-AAG-induced clathrinmediated endocytosis is the driving force.

PKC-mediated internalization is inhibited by cholesterol depletion 
To further investigate PKC-mediated ErbB2 internalization, cells were pre-incubated with methyl- $\beta$-cyclodextrin $(\mathrm{M} \beta \mathrm{CD})$ to deplete cholesterol before incubation with PMA. Flow cytometry showed that $\mathrm{M} \beta C D$ treatment in itself induced a slight reduction in the plasma membrane level of ErbB2, but importantly, there was no additional downregulation of ErbB2 upon PKC activation (Figure 6). This demonstrates that PMA-induced internalization of ErbB2 is sensitive to cholesterol depletion. Cholesterol depletion may affect several endocytic pathways. It has been shown to mildly inhibit EGFR endocytosis (Sigismund, Woelk et al. 2005, Kazazic, Roepstorff et al. 2006), and incubation with MBCD may perturb the formation of clathrin coated pits (Rodal, Skretting et al. 1999). However, as we find that PMA-induced ErbB2 internalization is clathrin-independent, we can exclude such side effects. The cholesterol dependence may indicate a role for lipid rafts, but the exact mechanisms involved in the internalization and a possible dependency of caveolin and/or other raft components, remains to be investigated.

Both PMA and 17-AAG decrease phosphorylation of ErbB2, but only 17-AAG induces ubiquitination

Phosphorylation and ubiquitination are important regulators of the stability and trafficking of, as well as signaling from, members of the ErbB family. It is well established that Hsp90 inhibitors like GA and 17-AAG induce ubiquitination of ErbB2 (Xu, Marcu et al. 2002, Zhou, Fernandes et al. 2003, Ehrlich, Wang et al. 2009) and it has been shown that incubation with GA can reduce ErbB2 tyrosine phosphorylation (Pust, Klokk et al. 2013). Furthermore, while PKC activation induces threonine phosphorylation of ErbB2, it can inhibit the ErbB2 kinase activity and reduce the constitutive ErbB2 tyrosine phosphorylation (Cao, Decker et al. 1991, Ouyang, Gulliford et al. 1998). However, whether PKCs have effect on ErbB2 ubiquitination has, to our knowledge, not been investigated. This is important to look into, as we have previously shown that ubiquitination can serve as endocytosis signal for ErbB2 (Vuong, Berger et al. 2013). Immunoprecipitation of ErbB2 upon incubation with 17-AAG or PMA confirmed the effects on ErbB2 tyrosine phosphorylation (Figure 7). PMA reduced the tyrosine phosphorylation to a similar extend as did 17-AAG, but importantly, contrary to 17AAG, PMA induced no measurable ErbB2 ubiquitination. Surprisingly, we found that Ro 318220 alone caused an increase in ErbB2 tyrosine phosphorylation (Figure 7A and B). This effect was weakened by combinatorial treatment of Ro 31-8220 and PMA, while combinatorial treatment of Ro 31-8220 and 17-AAG showed the same effect as 17-AAG treatment alone. The reason for this is unclear, but it has been shown that PKC-mediated threonine phosphorylation of EGFR shifts the monomeric versus dimeric state of EGFR towards monomers (Kluba, Engelborghs et al. 2015). It can thus be speculated that a basal PKC activity contributes to keeping ErbB2 as monomers and that Ro 31-8220 favors ErbB2 dimerization and activation.

As mentioned, ubiquitination was mainly driven by 17-AAG. While a combinatorial treatment with 17-AAG and PMA slightly increased the level of ubiquitination, 17-AAG and Ro 31-8220 in combination moderately decreased ubiquitination (Figure 7A and C). All other treatments showed no measurable ubiquitination. How PKCs can affect 17-AAG-induced ErbB2 ubiquitination when PMA or Ro 31-8220 alone has no effect, is unclear. However, as for phosphorylation, it can be speculated that it has to do with the monomeric versus dimeric state of ErbB2. Importantly, ubiquitination explains why we observe a clear degradation of ErbB2 whenever 17-AAG is present. Why the reduced ubiquitination after combinatorial treatment with 17-AAG and Ro 31-8220 did not have an effect on ErbB2 internalization and degradation is unclear, but it indicates that the concentration of 17-AAG used induces an 
ErbB2 ubiquitination sufficient for inducing ErbB2 internalization and degradation. The observed increased degradation when 17-AAG and PMA were combined do on the other hand support that increased ubiquitination causes increased lysosomal sorting of ErbB2, and importantly, it shows that the degradative sorting signal induced by $17-\mathrm{AAG}$ is superior to the stabilizing signal induced by PMA.

\section{Ro 31-8220 and PMA increase 17-AAG induced Hsp70 recruitment}

As described in the introduction, the exact role of Hsp90 in ErbB2 stabilization and as an inhibitor of ErbB2 internalization is still unclear. Hsp90 has been reported to retain ErbB2 at the plasma membrane through interaction with raft localized proteins like flotillins and members of the ERM protein family (Pust, Klokk et al. 2013, Asp, Kvalvaag et al. 2016). Furthermore, Hsp90 inhibitors are known to reduce the Hsp90-ErbB2 interaction at the same time as they increase recruitment of Hsp70 and ubiquitin ligases like CHIP and/or CUL5 (reviewed in Bertelsen and Stang 2014). Altogether, this could indicate that Hsp90 has to dissociate from ErbB2 before ErbB2 can be internalized. We therefore analyzed the amount of Hsp90 and Hsp70 which under different conditions co-immunoprecipitated with ErbB2 (Figure 8). As expected, 17-AAG mildly increased the recruitment of Hsp70, while Hsp90 interaction was clearly decreased. Hsp70 recruitment was even further increased when PMA or Ro 31-8220 were present along with 17-AAG, while the negative effect on Hsp90 interaction was partly counteracted by PMA, as well as Ro 31-8220. However, most importantly in this respect, neither PKC activation, nor PKC inhibition alone had any effect on the interaction between ErbB2 and Hsp90 or Hsp70.

\section{CONCLUSIONS}

Our data confirms that the otherwise endocytosis resistant ErbB2 can be internalized both upon Hsp90 inhibition and upon activation of PKCs, and that while Hsp90 inhibitors induce ErbB2 degradation, PKC activation induces stabilization. The different fates are most likely explained by different receptor modifications leading to internalization by different pathways, followed by differences in endosomal sorting. The 17-AAG data supports the notion that ubiquitination functions as a signal for clathrin-mediated internalization and ESCRTmediated sorting of ErbB2 to late endosomes and lysosomes for degradation. The exact mechanisms involved in PMA-induced internalization are less clear. Our data shows that the internalization is clathrin-independent and sensitive to cholesterol depletion. However, as several clathrin-independent pathways exist, and most, but not all, to varying degrees are cholesterol sensitive (for recent reviews see Sandvig, Torgersen et al. 2008, Mayor, Parton et al. 2014), the exact pathway remains to be identified. The cholesterol dependence and the previous identification of ErbB2 interaction with proteins like flotillins and ERMs can, however, indicate a role of lipid rafts in PMA-induced internalization. Another important regulator of internalization is dynamin. While clathrin-mediated endocytosis is dynamindependent both dynamin-dependent and -independent clathrin-independent pathways exist. The study by Bailey et al. indicated a role of Arf6 in PMA-induced ErbB2 trafficking (Bailey, Luan et al. 2014), and as Arf6-associated internalization has been shown to be cholesteroldependent, but dynamin-independent (Mayor, Parton et al. 2014), it will be important to include dynamin-dependence in follow-up studies.

Our results support the notion that an important effect of Hsp90 inhibitors is to recruit Hsp70 and ubiquitin ligases, and that ubiquitination serves as a signal for clathrin-mediated internalization and lysosomal sorting of ErbB2. Since the ErbB2-Hsp90 complex interacts with raft localized proteins, it is also likely that Hsp90 inhibitors have a dual function and 
serve to release ErbB2 from rafts. However, most importantly, our results from PMA-induced PKC activation show that Hsp90 does not have to dissociate for ErbB2 to be internalized. Since we find that PMA-induced internalization of ErbB2 is clathrin-independent it is possible that ErbB2 and Hsp90 remain in complex with raft components upon internalization, and that this may contribute to the alternative endosomal sorting of ErbB2. The role of rafts and the interaction between ErbB2 and raft components will thus be important follow-ups to this study. It will be especially important to study whether flotillins and ERM proteins are internalized along with ErbB2 upon PKC activation.

The morphology of the pericentrion has to our knowledge not been described previously. Bailey et al. suggest that the compartment serves as a hub for ErbB2-mediated signaling. For this to occur, the C-terminal part of ErbB2 has to be exposed into the cytosol. Our immunoEM data indicate that ErbB2 is internalized to enlarged, empty, early endosome like compartments and further sorted to a tubulovesicular or cisternal compartment which shows morphological resemblance with previously described ERCs. Contrary to the localization of ErbB2 to inner vesicles of MVBs, which is seen upon incubation with 17-AAG, the Cterminal part of ErbB2 will in these compartments be exposed to the cytosol and signal transduction may occur. The sustained downregulation further indicates that ErbB2 is retained in this compartment. Why it is not recycled is unclear, but for the EGFR it has been shown that the retention depends on PKC-mediated Thr-654 phosphorylation. We did not study PMA-induced Thr phosphorylation, but since PKCs can induce phosphorylation at Thr-686 in ErbB2, it is likely that ErbB2 is retained by mechanisms similar to those retaining EGFR.

Acknowledgements: The work was supported by the South-Eastern Norway Regional Health Authority (M. Dietrich, grant \#2013019), the Norwegian Cancer Society (F. Nikolaysen; grant \#4474487), UNIFOR, Anders Jahre's Foundation for the Promotion of Sciences, and the Olav Raagholt and Gerd Meidel Raagholt Research Foundation.

Conflict of interest: The authors declare that they have no conflicts of interest with the contents of this article. 


\section{References}

Alvi, F., J. Idkowiak-Baldys, A. Baldys, J. R. Raymond and Y. A. Hannun (2007). "Regulation of membrane trafficking and endocytosis by protein kinase $\mathrm{C}$ : emerging role of the pericentrion, a novel protein kinase C-dependent subset of recycling endosomes." Cell Mol Life Sci 64(3): 263-270.

Asp, N., A. Kvalvaag, K. Sandvig and S. Pust (2016). "Regulation of ErbB2 localization and function in breast cancer cells by ERM proteins." Oncotarget 7(18): 25443-25460.

Austin, C. D., A. M. De Maziere, P. I. Pisacane, S. M. van Dijk, C. Eigenbrot, M. X. Sliwkowski, J. Klumperman and R. H. Scheller (2004). "Endocytosis and sorting of ErbB2 and the site of action of cancer therapeutics trastuzumab and geldanamycin." Mol Biol Cell 15(12): 5268-5282.

Bailey, T. A., H. Luan, E. Tom, T. A. Bielecki, B. Mohapatra, G. Ahmad, M. George, D. L. Kelly, A. Natarajan, S. M. Raja, V. Band and H. Band (2014). "A kinase inhibitor screen reveals protein kinase C-dependent endocytic recycling of ErbB2 in breast cancer cells." J Biol Chem 289(44): 30443-30458.

Bao, J., I. Alroy, H. Waterman, E. D. Schejter, C. Brodie, J. Gruenberg and Y. Yarden (2000). "Threonine phosphorylation diverts internalized epidermal growth factor receptors from a degradative pathway to the recycling endosome." J Biol Chem 275(34): 26178-26186.

Baulida, J., M. H. Kraus, M. Alimandi, P. P. Di Fiore and G. Carpenter (1996). "All ErbB receptors other than the epidermal growth factor receptor are endocytosis impaired." J Biol Chem 271(9): 52515257.

Bertelsen, V. and E. Stang (2014). "The Mysterious Ways of ErbB2/HER2 Trafficking." Membranes (Basel) 4(3): 424-446.

Cao, H., S. Decker and D. F. Stern (1991). "TPA inhibits the tyrosine kinase activity of the neu protein in vivo and in vitro." Oncogene 6(5): 705-711.

Citri, A., J. Gan, Y. Mosesson, G. Vereb, J. Szollosi and Y. Yarden (2004). "Hsp90 restrains ErbB2/HER2 signalling by limiting heterodimer formation." EMBO Rep 5(12): 1165-1170.

Ehrlich, E. S., T. Wang, K. Luo, Z. Xiao, A. M. Niewiadomska, T. Martinez, W. Xu, L. Neckers and X. F. Yu (2009). "Regulation of Hsp90 client proteins by a Cullin5-RING E3 ubiquitin ligase." Proc Natl Acad Sci U S A 106(48): 20330-20335.

Fortian, A., L. K. Dionne, S. H. Hong, W. Kim, S. P. Gygi, S. C. Watkins and A. Sorkin (2015). "Endocytosis of Ubiquitylation-Deficient EGFR Mutants via Clathrin-Coated Pits is Mediated by Ubiquitylation." Traffic 16(11): 1137-1154.

Fosdahl, A. M., M. Dietrich, K. O. Schink, M. S. Malik, M. Skeie, V. Bertelsen and E. Stang (2017). "ErbB3 interacts with Hrs and is sorted to lysosomes for degradation." Biochim Biophys Acta 1864(12): 2241-2252.

Garrett, T. P., N. M. McKern, M. Lou, T. C. Elleman, T. E. Adams, G. O. Lovrecz, M. Kofler, R. N. Jorissen, E. C. Nice, A. W. Burgess and C. W. Ward (2003). "The crystal structure of a truncated ErbB2 ectodomain reveals an active conformation, poised to interact with other ErbB receptors." Mol Cell 11(2): 495-505.

Graus-Porta, D., R. R. Beerli, J. M. Daly and N. E. Hynes (1997). "ErbB-2, the preferred heterodimerization partner of all ErbB receptors, is a mediator of lateral signaling." EMBO J 16(7): 1647-1655.

Griffiths, G., A. McDowall, R. Back and J. Dubochet (1984). "On the preparation of cryosections for immunocytochemistry." J Ultrastruct Res 89(1): 65-78.

Haslekas, C., K. Breen, K. W. Pedersen, L. E. Johannessen, E. Stang and I. H. Madshus (2005). "The inhibitory effect of ErbB2 on epidermal growth factor-induced formation of clathrin-coated pits correlates with retention of epidermal growth factor receptor-ErbB2 oligomeric complexes at the plasma membrane." Molecular Biology of the Cell 16(12): 5832-5842.

Hommelgaard, A. M., M. Lerdrup and B. van Deurs (2004). "Association with membrane protrusions makes ErbB2 an internalization-resistant receptor." Mol Biol Cell 15(4): 1557-1567.

Huang, F., A. Khvorova, W. Marshall and A. Sorkin (2004). "Analysis of clathrin-mediated endocytosis of epidermal growth factor receptor by RNA interference." J Biol Chem 279(16): 1665716661 .

Hughes, J. B., C. Berger, M. S. Rodland, M. Hasmann, E. Stang and I. H. Madshus (2009). "Pertuzumab increases epidermal growth factor receptor down-regulation by counteracting epidermal growth factor receptor-ErbB2 heterodimerization." Molecular Cancer Therapeutics 8(7): 1885-1892. Idkowiak-Baldys, J., K. P. Becker, K. Kitatani and Y. A. Hannun (2006). "Dynamic sequestration of the recycling compartment by classical protein kinase C." J Biol Chem 281(31): 22321-22331.

Jeong, J., W. Kim, L. K. Kim, J. VanHouten and J. J. Wysolmerski (2017). "HER2 signaling regulates HER2 localization and membrane retention." PLoS One 12(4): e0174849. 
Jeong, J., J. N. VanHouten, P. Dann, W. Kim, C. Sullivan, H. Yu, L. Liotta, V. Espina, D. F. Stern, P. A. Friedman and J. J. Wysolmerski (2016). "PMCA2 regulates HER2 protein kinase localization and signaling and promotes HER2-mediated breast cancer." Proc Natl Acad Sci U S A 113(3): E282-290.

Jeong, J., J. N. VanHouten, W. Kim, P. Dann, C. Sullivan, J. Choi, W. B. Sneddon, P. A. Friedman and J. J. Wysolmerski (2017). "The scaffolding protein NHERF1 regulates the stability and activity of the tyrosine kinase HER2." J Biol Chem 292(16): 6555-6568.

Kazazic, M., K. Roepstorff, L. E. Johannessen, N. M. Pedersen, B. van Deurs, E. Stang and I. H. Madshus (2006). "EGF-induced activation of the EGF receptor does not trigger mobilization of caveolae." Traffic 7(11): 1518-1527.

Kluba, M., Y. Engelborghs, J. Hofkens and H. Mizuno (2015). "Inhibition of Receptor Dimerization as a Novel Negative Feedback Mechanism of EGFR Signaling." PLoS One 10(10): e0139971.

Le, X. F., M. Marcelli, A. McWatters, B. Nan, G. B. Mills, C. A. O'Brian and R. C. Bast, Jr. (2001). "Heregulin-induced apoptosis is mediated by down-regulation of Bcl-2 and activation of caspase-7 and is potentiated by impairment of protein kinase C alpha activity." Oncogene 20(57): 8258-8269.

Lerdrup, M., S. Bruun, M. V. Grandal, K. Roepstorff, M. M. Kristensen, A. M. Hommelgaard and B. van Deurs (2007). "Endocytic down-regulation of ErbB2 is stimulated by cleavage of its C-terminus." Mol Biol Cell 18(9): 3656-3666.

Lerdrup, M., A. M. Hommelgaard, M. Grandal and B. van Deurs (2006). "Geldanamycin stimulates internalization of ErbB2 in a proteasome-dependent way." J Cell Sci 119(Pt 1): 85-95.

Liu, M., J. Idkowiak-Baldys, P. L. Roddy, A. Baldys, J. Raymond, C. J. Clarke and Y. A. Hannun (2013). "Sustained activation of protein kinase C induces delayed phosphorylation and regulates the fate of epidermal growth factor receptor." PLoS One 8(11): e80721.

Llado, A., P. Timpson, S. Vila de Muga, J. Moreto, A. Pol, T. Grewal, R. J. Daly, C. Enrich and F. Tebar (2008). "Protein kinase Cdelta and calmodulin regulate epidermal growth factor receptor recycling from early endosomes through Arp2/3 complex and cortactin." Mol Biol Cell 19(1): 17-29.

Longva, K. E., N. M. Pedersen, C. Haslekas, E. Stang and I. H. Madshus (2005). "Herceptin-induced inhibition of ErbB2 signaling involves reduced phosphorylation of Akt but not endocytic downregulation of ErbB2." Int J Cancer 116(3): 359-367.

Mayor, S., R. G. Parton and J. G. Donaldson (2014). "Clathrin-independent pathways of endocytosis." Cold Spring Harb Perspect Biol 6(6).

Mochly-Rosen, D., K. Das and K. V. Grimes (2012). "Protein kinase C, an elusive therapeutic target?" Nat Rev Drug Discov 11(12): 937-957.

Ouyang, X. M., T. Gulliford and R. J. Epstein (1998). "The duration of phorbol-inducible ErbB2 tyrosine dephosphorylation parallels that of receptor endocytosis rather than threonine-686 phosphorylation: implications for the physiological role of protein kinase $\mathrm{C}$ in growth factor receptor signalling." Carcinogenesis 19(11): 2013-2019.

Pedersen, N. M., K. Breen, M. S. Rodland, C. Haslekas, E. Stang and I. H. Madshus (2009). "Expression of epidermal growth factor receptor or ErbB3 facilitates geldanamycin-induced downregulation of ErbB2." Mol Cancer Res 7(2): 275-284.

Pedersen, N. M., I. H. Madshus, C. Haslekas and E. Stang (2008). "Geldanamycin-induced downregulation of ErbB2 from the plasma membrane is clathrin dependent but proteasomal activity independent." Mol Cancer Res 6(3): 491-500.

Prekeris, R., J. Klumperman, Y. A. Chen and R. H. Scheller (1998). "Syntaxin 13 mediates cycling of plasma membrane proteins via tubulovesicular recycling endosomes." J Cell Biol 143(4): 957-971.

Pust, S., T. I. Klokk, N. Musa, M. Jenstad, B. Risberg, B. Erikstein, L. Tcatchoff, K. Liestol, H. E. Danielsen, B. van Deurs and K. Sandvig (2013). "Flotillins as regulators of ErbB2 levels in breast cancer." Oncogene 32(29): 3443-3451.

Rodal, S. K., G. Skretting, Ø. Garred, F. Vilhardt, B. van Deurs and K. Sandvig (1999). "Extraction of Cholesterol with Methyl- $\beta$-Cyclodextrin Perturbs Formation of Clathrin-coated Endocytic Vesicles." Molecular Biology of the Cell 10(4): 961-974.

Roepstorff, K., L. Grovdal, M. Grandal, M. Lerdrup and B. van Deurs (2008). "Endocytic downregulation of ErbB receptors: mechanisms and relevance in cancer." Histochem Cell Biol 129(5): 563-578.

Rosse, C., M. Linch, S. Kermorgant, A. J. Cameron, K. Boeckeler and P. J. Parker (2010). "PKC and the control of localized signal dynamics." Nat Rev Mol Cell Biol 11(2): 103-112.

Sak, M. M., M. Szymanska, V. Bertelsen, M. Hasmann, I. H. Madshus and E. Stang (2013). "Pertuzumab counteracts the inhibitory effect of ErbB2 on degradation of ErbB3." Carcinogenesis 34(9): 2031-2038.

Sandvig, K., M. L. Torgersen, H. A. Raa and B. van Deurs (2008). "Clathrin-independent endocytosis: from nonexisting to an extreme degree of complexity." Histochem Cell Biol 129(3): 267-276. 
Sigismund, S., V. Algisi, G. Nappo, A. Conte, R. Pascolutti, A. Cuomo, T. Bonaldi, E. Argenzio, L. G. Verhoef, E. Maspero, F. Bianchi, F. Capuani, A. Ciliberto, S. Polo and P. P. Di Fiore (2013). "Threshold-controlled ubiquitination of the EGFR directs receptor fate." EMBO J 32(15): 2140-2157. Sigismund, S., T. Woelk, C. Puri, E. Maspero, C. Tacchetti, P. Transidico, P. P. Di Fiore and S. Polo (2005). "Clathrin-independent endocytosis of ubiquitinated cargos." Proc Natl Acad Sci U S A 102(8): 2760-2765.

Sorkin, A. and L. K. Goh (2009). "Endocytosis and intracellular trafficking of ErbBs." Exp Cell Res 315(4): 683-696.

Szymanska, M., A. M. Fosdahl, C. Raiborg, M. Dietrich, K. Liestøl, E. Stang and V. Bertelsen (2016). "Interaction with epsin 1 regulates the constitutive clathrin-dependent internalization of ErbB3." Biochimica et Biophysica Acta (BBA) - Molecular Cell Research 1863(6, Part A): 1179-1188.

Tikhomirov, O. and G. Carpenter (2000). "Geldanamycin induces ErbB-2 degradation by proteolytic fragmentation." J Biol Chem 275(34): 26625-26631.

Tikhomirov, O. and G. Carpenter (2003). "Identification of ErbB-2 kinase domain motifs required for geldanamycin-induced degradation." Cancer Res 63(1): 39-43.

Vercauteren, D., R. E. Vandenbroucke, A. T. Jones, J. Rejman, J. Demeester, S. C. De Smedt, N. N. Sanders and K. Braeckmans (2010). "The use of inhibitors to study endocytic pathways of gene carriers: optimization and pitfalls." Mol Ther 18(3): 561-569.

Vuong, T. T., C. Berger, V. Bertelsen, M. S. Rodland, E. Stang and I. H. Madshus (2013). "Preubiquitinated chimeric ErbB2 is constitutively endocytosed and subsequently degraded in lysosomes." Exp Cell Res 319(3): 32-45.

Wang, X. Q., Q. Yan, P. Sun, J. W. Liu, L. Go, S. M. McDaniel and A. S. Paller (2007). "Suppression of epidermal growth factor receptor signaling by protein kinase C-alpha activation requires CD82, caveolin-1, and ganglioside." Cancer Res 67(20): 9986-9995.

Xu, W., M. Marcu, X. Yuan, E. Mimnaugh, C. Patterson and L. Neckers (2002). "Chaperonedependent E3 ubiquitin ligase CHIP mediates a degradative pathway for c-ErbB2/Neu." Proc Natl Acad Sci U S A 99(20): 12847-12852.

Xu, W., X. Yuan, Z. Xiang, E. Mimnaugh, M. Marcu and L. Neckers (2005). "Surface charge and hydrophobicity determine ErbB2 binding to the Hsp90 chaperone complex." Nat Struct Mol Biol 12(2): 120-126.

Zhou, P., N. Fernandes, I. L. Dodge, A. L. Reddi, N. Rao, H. Safran, T. A. DiPetrillo, D. E. Wazer, V. Band and H. Band (2003). "ErbB2 degradation mediated by the co-chaperone protein CHIP." J Biol Chem 278(16): 13829-13837. 
Table 1

\begin{tabular}{|c|c|c|c|c|c|}
\hline & \multicolumn{5}{|c|}{ Distribution of labeling } \\
\hline Condition $\quad$ Organelle & $\begin{array}{l}\text { Multivesicular } \\
\text { body }\end{array}$ & $\begin{array}{c}\text { Early } \\
\text { endosome }\end{array}$ & $\begin{array}{l}\text { Tubular/ } \\
\text { cisternal }\end{array}$ & Golgi & $\begin{array}{c}\text { Not } \\
\text { characterized }\end{array}$ \\
\hline 17-AAG & $42.3 \pm 0.4$ & $8.1 \pm 3.5$ & $12.5 \pm 2.8$ & $2.9 \pm 0.3$ & $34.2 \pm 1.1$ \\
\hline PMA & $6.3 \pm 2.3$ & $6.7 \pm 2.5$ & $49.5 \pm 4.6$ & $0.6 \pm 0.4$ & $36.9 \pm 9.3$ \\
\hline 17-AAG + PMA & $70.2 \pm 5.1$ & $1.0 \pm 0.3$ & $3.5 \pm 1.2$ & $1.1 \pm 0.2$ & $24.2 \pm 4.6$ \\
\hline
\end{tabular}

SK-BR-3 cells, treated as indicated for $4 \mathrm{~h}$ at $37^{\circ} \mathrm{C}$, were prepared for immuno-EM. Sections were labeled using an antibody to the extracellular part of ErbB2 (TAB250), and the percentage distribution of gold particles localized to the indicated compartments was quantified. The results show the mean \pm SD from three parallel labeling experiments. 


\section{Figure legends}

Figure 1. 17-AAG and PMA downregulate ErbB2 from the plasma membrane, but only 17-AAG induces degradation of ErbB2. SK-BR-3 cells were left untreated or pre-incubated with CHX $(25 \mu \mathrm{g} / \mathrm{ml})$ for $15 \mathrm{~min}$ before addition of DMSO (vehicle control), PMA (100 nM) and/or 17-AAG $(3 \mu \mathrm{M})$ for indicated time points. (A) Fixed non-permeabilized cells were stained with an antibody to ErbB2 (24D2) and subjected to flow cytometry. Data from 3 experiments were normalized to untreated cells and pooled. Mean values \pm SD were plotted. * $\mathrm{p}<0.05, * * \mathrm{p}<0.01, * * * \mathrm{p}<0.001$. (B) Cell lysates were subjected to immunoblotting using antibodies to ErbB2 intracellular domain (i.c.) (PAD:Z4881), ErbB2 extracellular domain (e.c.) (42), PKC $\alpha, \mathrm{PKC} \delta$ and tubulin (loading control). (C-D) Net luminescence of the bands corresponding to ErbB2 i.c. (C) and ErbB2 e.c. (D) in B was quantified, normalized to tubulin and plotted normalized to the ErbB2 level in cells not exposed to CHX. The quantifications represent data from three independent experiments and are shown as mean $\pm \mathrm{SD}$. $* \mathrm{p}<0.05$, $* * \mathrm{p}<0.01 . * * * \mathrm{p}<0.001$.

Figure 2. PKC inhibition blocks PMA-induced, but not 17-AAG induced internalization of ErbB2. SK-BR-3 cells were left untreated or pre-incubated with CHX ( $25 \mu \mathrm{g} / \mathrm{ml})$ for 15 min before addition of DMSO (vehicle control), PMA (100 nM), Ro 31-8220 $(1 \mu \mathrm{M})$ and/or 17-AAG $(3 \mu \mathrm{M})$ for indicated time points. (A) Fixed non-permeabilized cells were stained with an antibody to ErbB2 (24D2) and subjected to flow cytometry. Data from 3 experiments were normalized to untreated cells and pooled. Mean values \pm SD were plotted. $* \mathrm{p}<0.05$, ** $\mathrm{p}<0.01$. $* * * \mathrm{p}<0.001$. (B) Cell lysates were subjected to immunoblotting using antibodies to ErbB2 intracellular domain (i.c.) (PAD:Z4881), PKC $\alpha, \mathrm{PKC} \delta$ and tubulin (loading control). (C) Net luminescence of the bands corresponding to ErbB2 i.c. in B was quantified, normalized to tubulin and plotted normalized to the ErbB2 level in cells not exposed to CHX. The quantifications represent data from three independent experiments and are shown as mean \pm SD.

Figure 3. Both PMA and 17-AAG induce internalization of Herceptin. SK-BR-3 cells, pre-incubated with the anti-ErbB2 antibody Herceptin for $30 \mathrm{~min}$ on ice, were further incubated with 17-AAG $(3 \mu \mathrm{M})$ or PMA $(100 \mathrm{nM})$ alone or in combination for 4 hours at $37^{\circ} \mathrm{C}$. Incubation with DMSO was used as control. Localization of Herceptin was detected by staining with an anti-human IgG antibody. (A) Early endosomes were localized by staining for EEA1. (B) Late endosomes/lysosomes were localized by staining for LAMP1. The cells were analyzed by confocal microscopy. Insets show high magnifications of the corresponding framed areas. Scale bars $20 \mu \mathrm{m}$. Micrographs representative for three independent experiments are shown.

Figure 4. ErbB2 localizes to complex tubulovesicular compartments upon incubation with PMA. SK-BR-3 cells were incubated with or without 17-AAG (3 $\mu$ M) or PMA (100 $\mathrm{nM}$ ) for $4 \mathrm{~h}$ before fixation and preparation for immuno-EM labeling. Sections were labeled with an antibody to the extracellular domain of ErbB2 (TAB250). (A) Control cells. The picture was chosen to show that minor amounts of labeling could be seen in endosomes (e.e. early endosome). (B) 17-AAG treated cells. ErbB2 gets concentrated in MVBs. (C-F) PMA treated cells. ErbB2 localizes to enlarged early endosomes and in tubulovesicular or cisternal compartments. Scale bars $100 \mathrm{~nm}$ 
Figure 5. 17-AAG- but not PMA-induced downregulation of ErbB2 is clathrin dependent. PAE.ErbB2 cells were transfected with non-targeting (NT) siRNA or with siRNA to CHC. Cells were pre-incubated with CHX $(25 \mu \mathrm{g} / \mathrm{ml})$ for $15 \mathrm{~min}$ before addition of DMSO (vehicle control), PMA $(100 \mathrm{nM})$ and/or 17-AAG $(3 \mu \mathrm{M})$ for indicated time points. Fixed non-permeabilized cells were stained with an antibody to ErbB2 (24D2) and subjected to flow cytometry. Data from 3 experiments were normalized to untreated cells and pooled. Mean values \pm SD were plotted. $* \mathrm{p}<0.05, * * \mathrm{p}<0.01$

Figure 6. Cholesterol depletion inhibits PMA-induced internalization of ErbB2.

PAE.ErbB2 cells were left untreated or pre-incubated with CHX $(25 \mu \mathrm{g} / \mathrm{ml})(\mathrm{A})$ or CHX and $10 \mathrm{mM}$ Methyl- $\beta$-cyclodextrin $(\mathrm{M} \beta \mathrm{CD}$ ) (B) for $15 \mathrm{~min}$ before addition of DMSO (vehicle control) or PMA (100 nM) for indicated time points. Fixed non-permeabilized cells were stained with an antibody to ErbB2 (24D2) and subjected to flow cytometry. Data from 3 experiments were normalized to untreated cells and pooled. Mean values \pm SD were plotted. n.s. non-significant, $* \mathrm{p}<0.05, * * \mathrm{p}<0.01 . * * * \mathrm{p}<0.001$.

Figure 7. 17-AAG but not PMA induce ubiquitination of ErbB2. SK-BR-3 cells, preincubated for $15 \mathrm{~min}$ with or without Ro 31-8220 $(1 \mu \mathrm{M})$, were further incubated for $60 \mathrm{~min}$ with or without 17-AAG $(3 \mu \mathrm{M})$ and/or PMA $(100 \mathrm{nM})$. Cell lysates were subjected to immunoprecipitation under denaturing conditions using magnetic beads coated with an antiErbB2 (PAD:Z4881) specific antibody. Non-coated beads were used as control (-Ab). The immunoprecipitated proteins were immunoblotted using antibodies to ubiquitin ( $\mathrm{Ub}$ ). The membrane was stripped and blotted for phosphorylated tyrosine (pY), stripped again and blotted for ErbB2 (PAD:Z4881). One representative experiment out of three is shown. (B-C) Net luminescence of the bands corresponding to phosphorylated tyrosine (B) and ubiquitin (C) were quantified and normalized to immunoprecipitated ErbB2. Normalized values were plotted as ratios of control (untreated) (B) or 17-AAG (C). Data shown as mean \pm SD and is representative of three independent experiments. n.s. non-significant, $* \mathrm{p}<0.05, * * \mathrm{p}<0.01$. $* * * \mathrm{p}<0.001$.

Figure 8. PMA does not induce Hsp90 dissociation from ErbB2. SK-BR-3 cells, preincubated for $15 \mathrm{~min}$ with or without Ro 31-8220 $(1 \mu \mathrm{M})$, were further incubated for $60 \mathrm{~min}$ with or without 17-AAG $(3 \mu \mathrm{M})$ and/or PMA $(100 \mathrm{nM})$. Cell lysates were subjected to immunoprecipitation using magnetic beads coated with an anti-ErbB2 (29D8) specific antibody. Non-coated beads were used as control $(-\mathrm{Ab})$. The immunoprecipitated proteins were analyzed by immunoblotting using antibodies to ErbB2 (PAD:Z4881), Hsp70 and Hsp90. Cell lysates were immunoblotted using antibodies to ErbB2, Hsp70, Hsp90 and tubulin (loading control). The data represent one representative set of experiments out of three. (B-C) Net luminescence of the bands corresponding to Hsp70 (B) and Hsp90 (C) were quantified and normalized to immunoprecipitated ErbB2. Normalized values were plotted as ratios of control (untreated). Data shown as mean $\pm \mathrm{SD}$ and is representative of three independent experiments. n.s. non-significant, $* \mathrm{p}<0.05, * * \mathrm{p}<0.01$. 
Figure 1

A

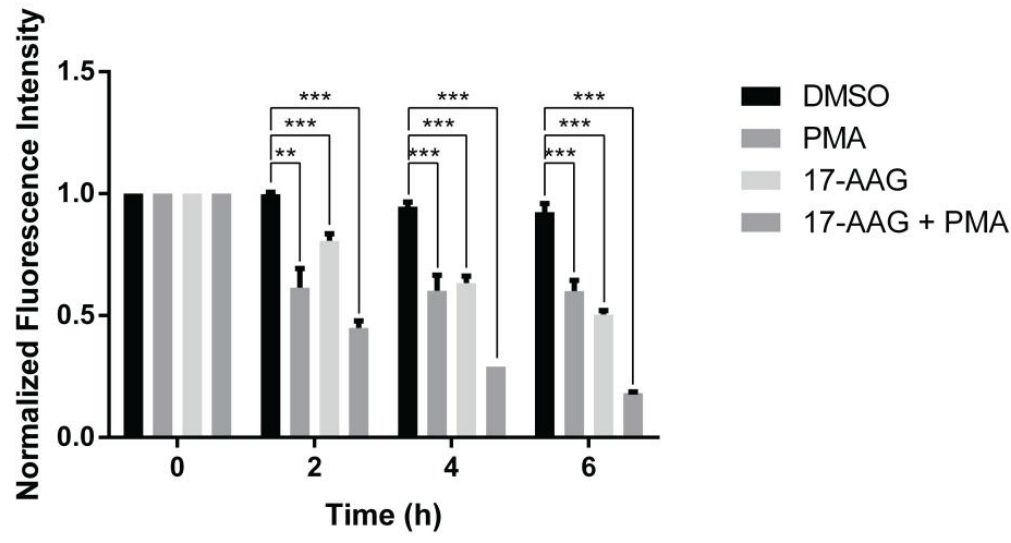

B
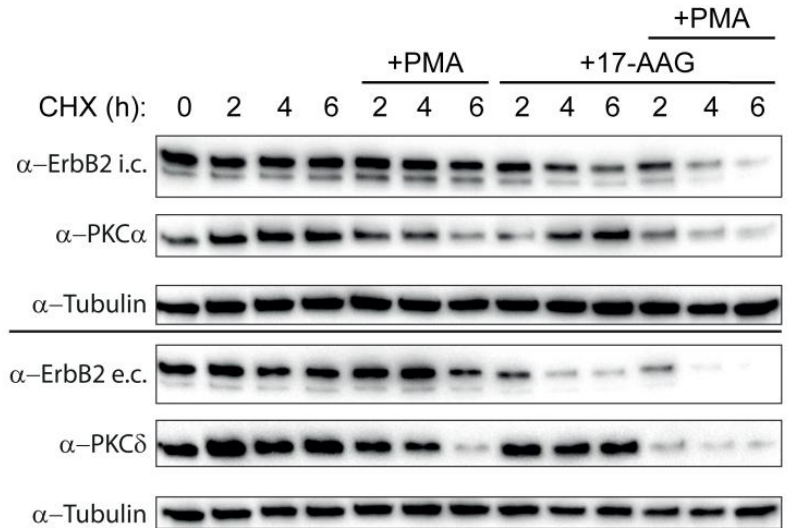

C

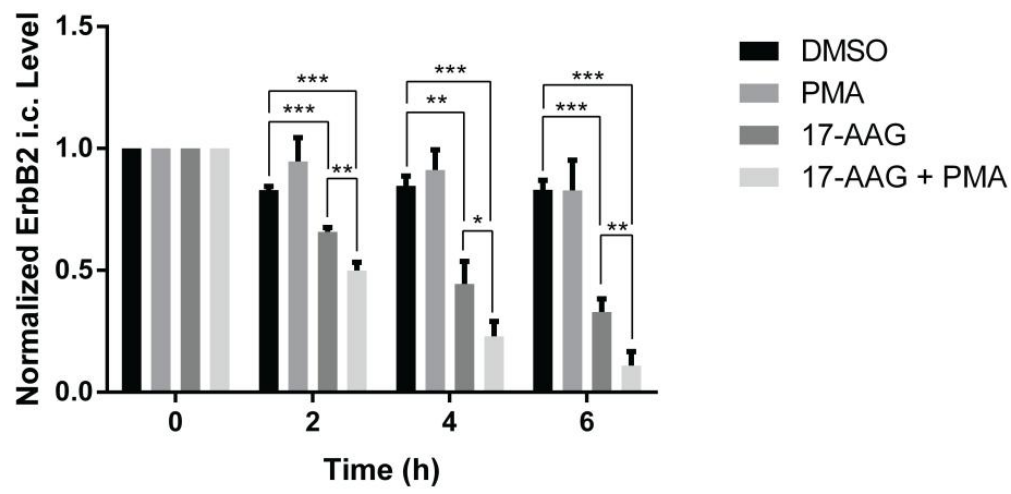

D

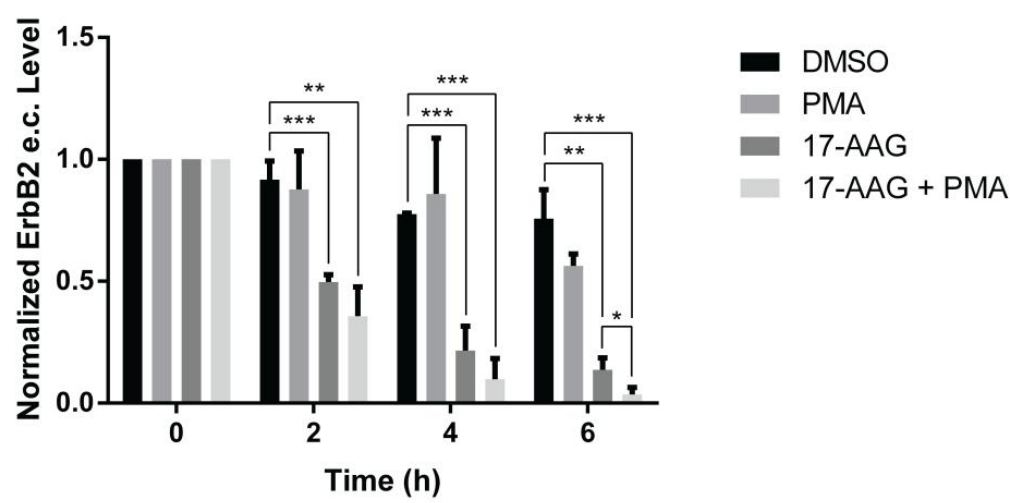


Figure 2

A

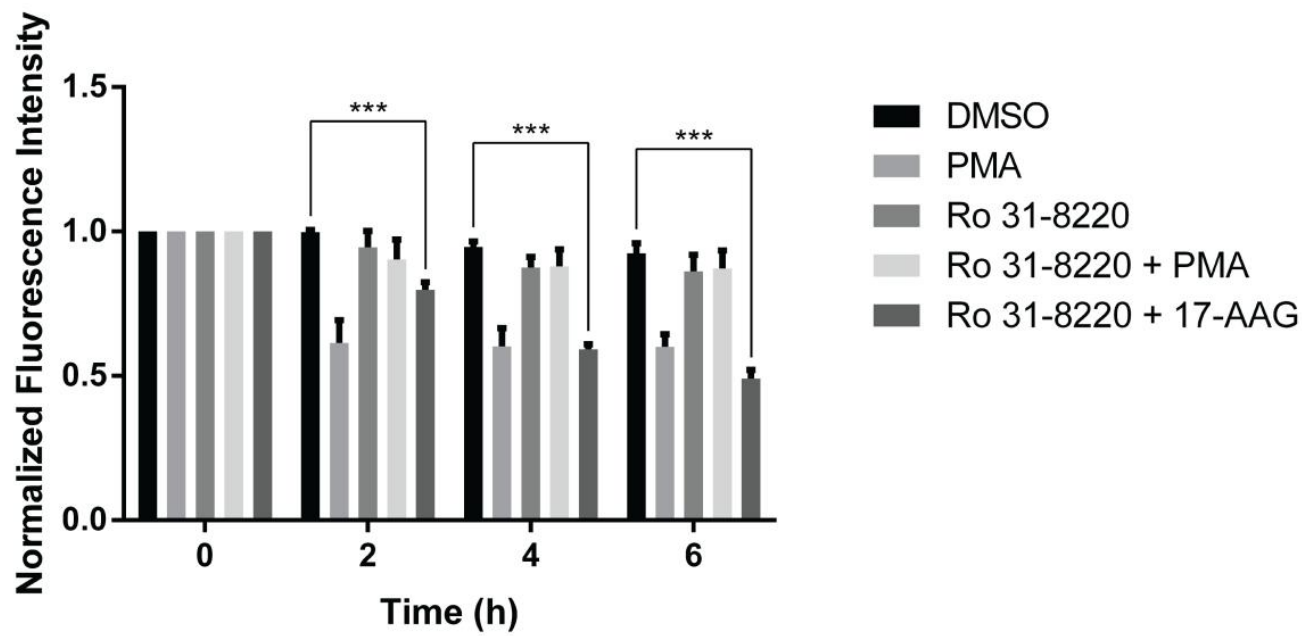

B

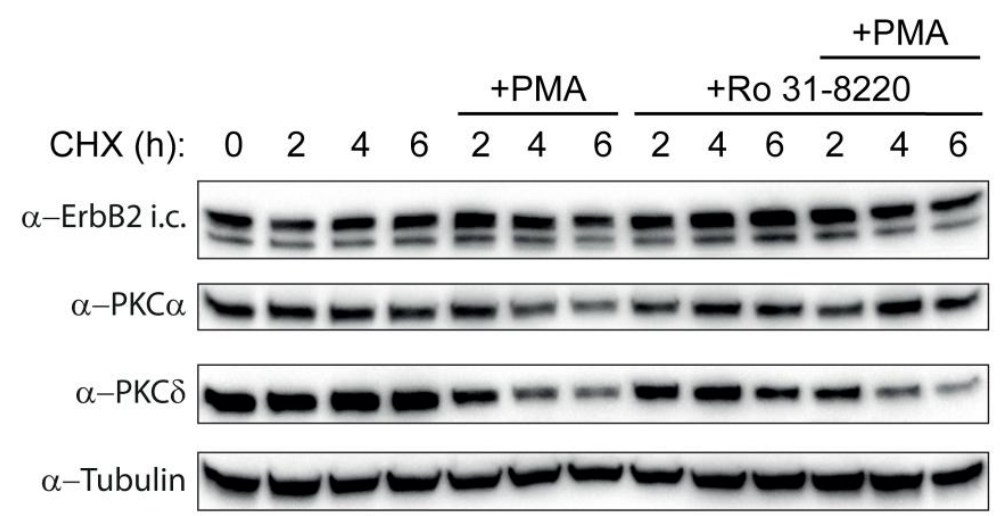

C

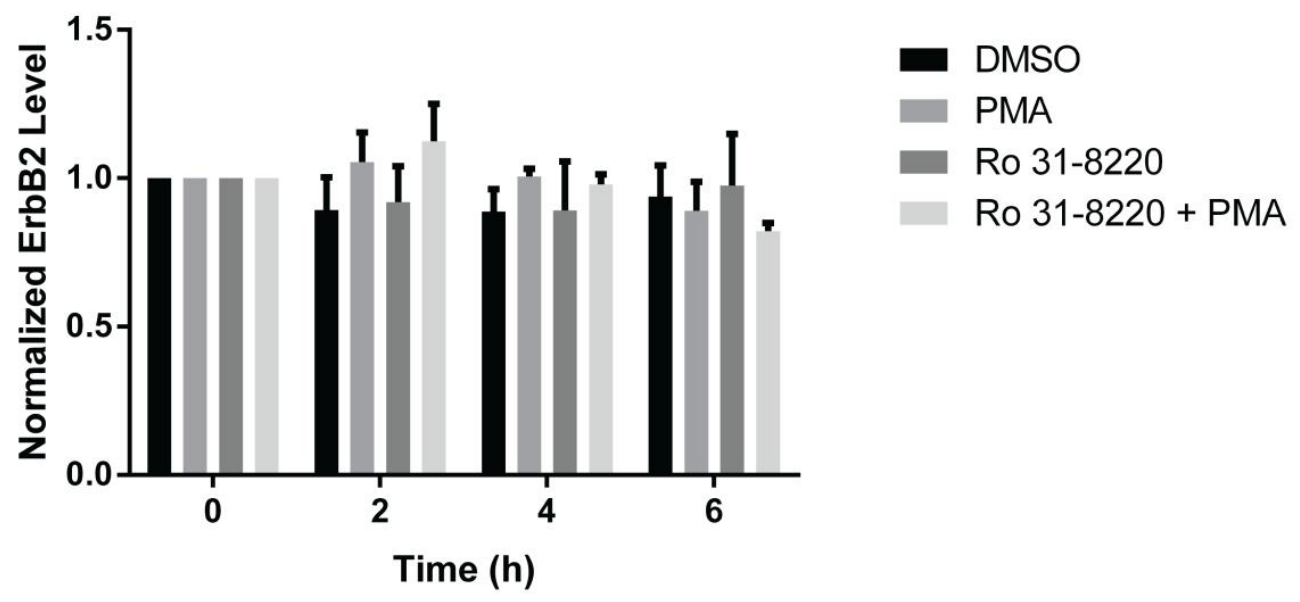


Figure 3

A
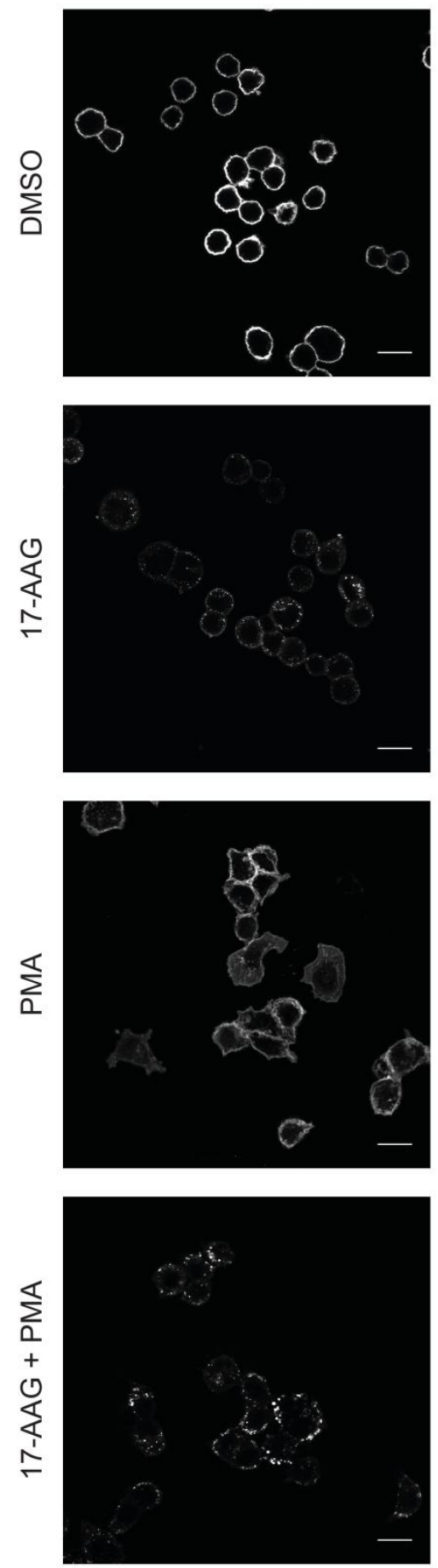

EEA1
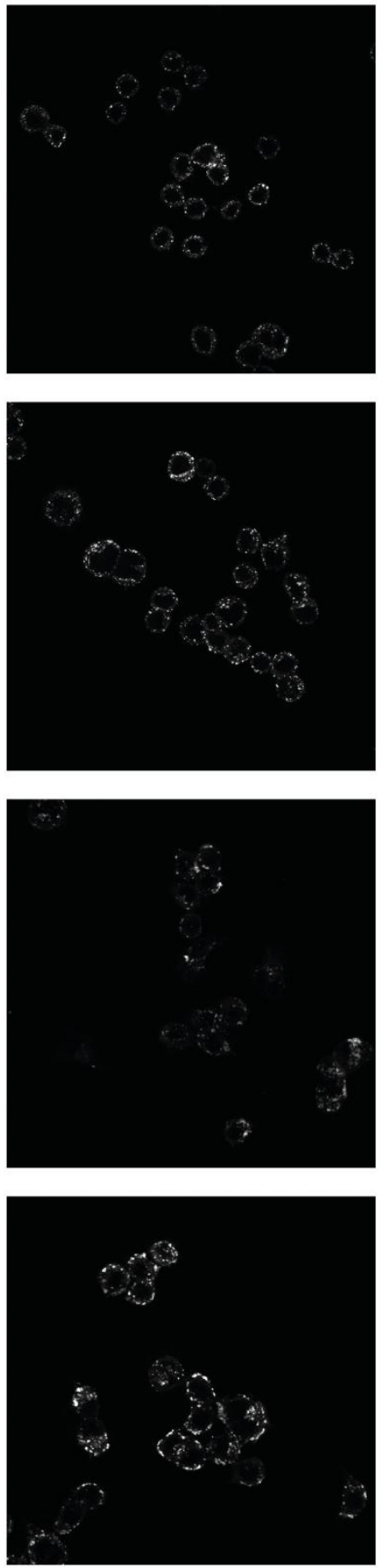

Merge
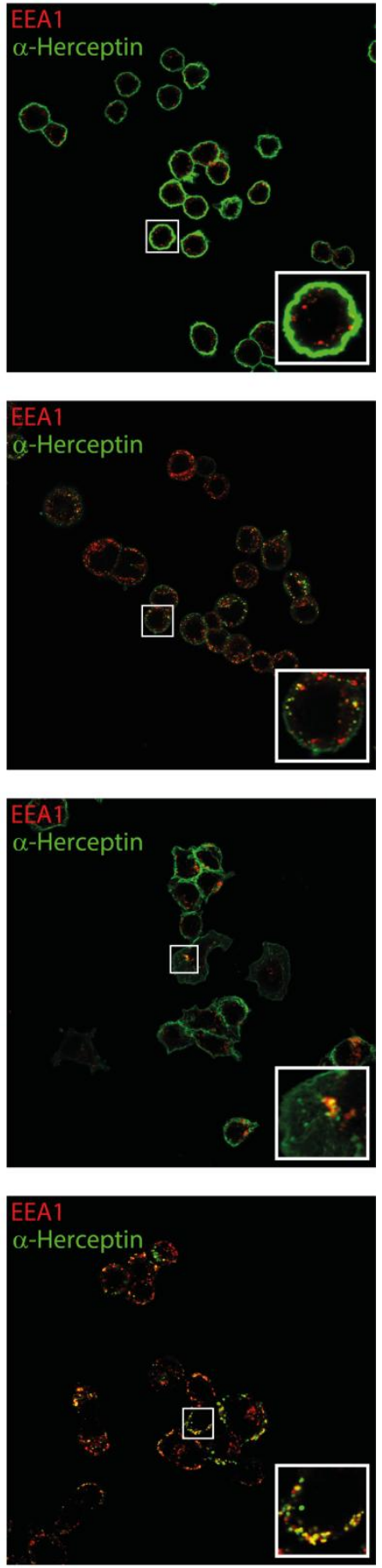

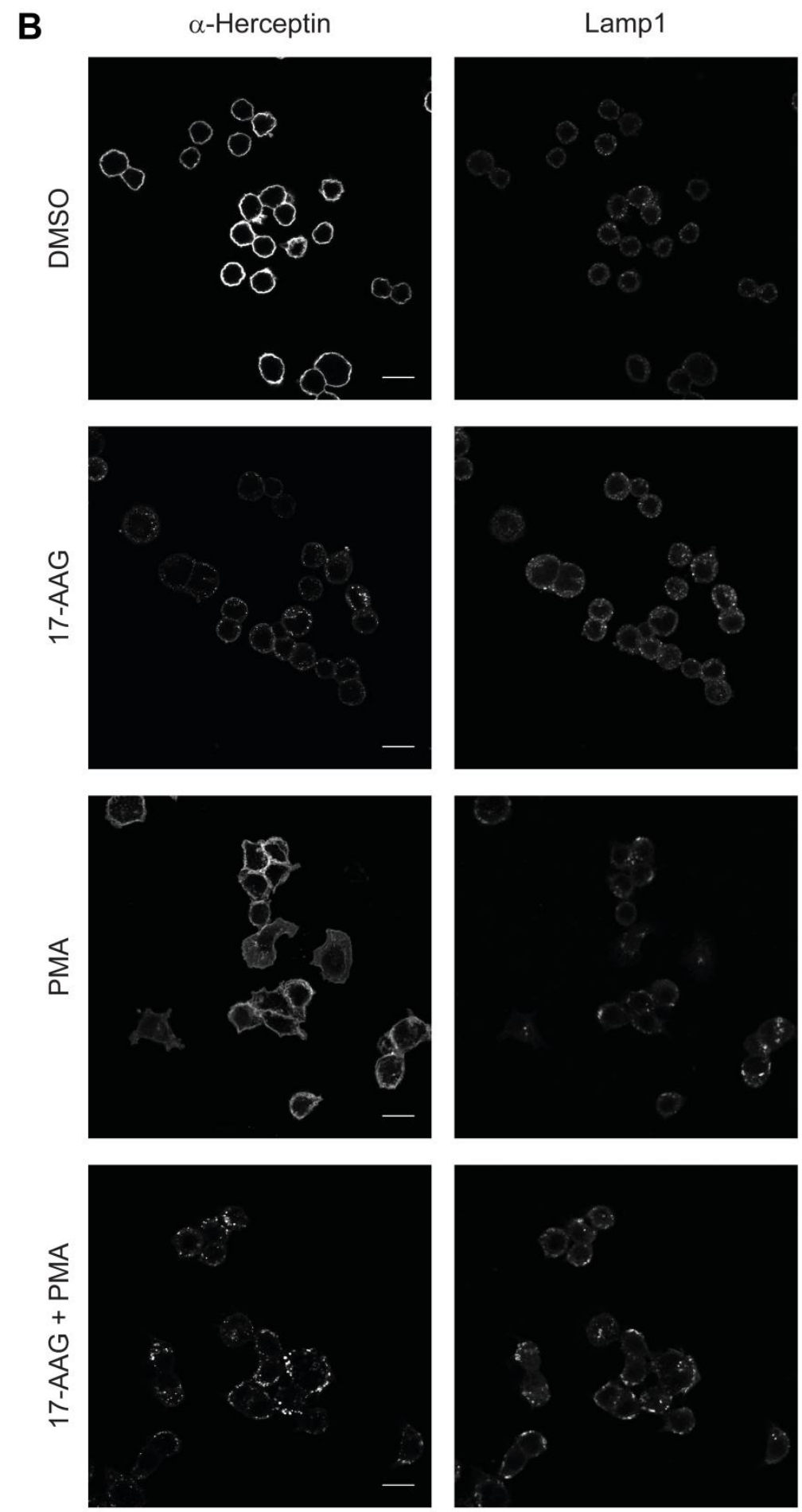

Lamp1

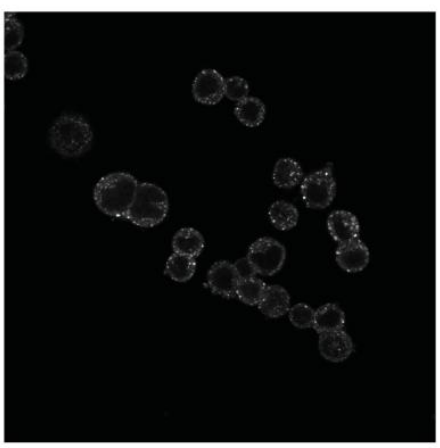

Merge
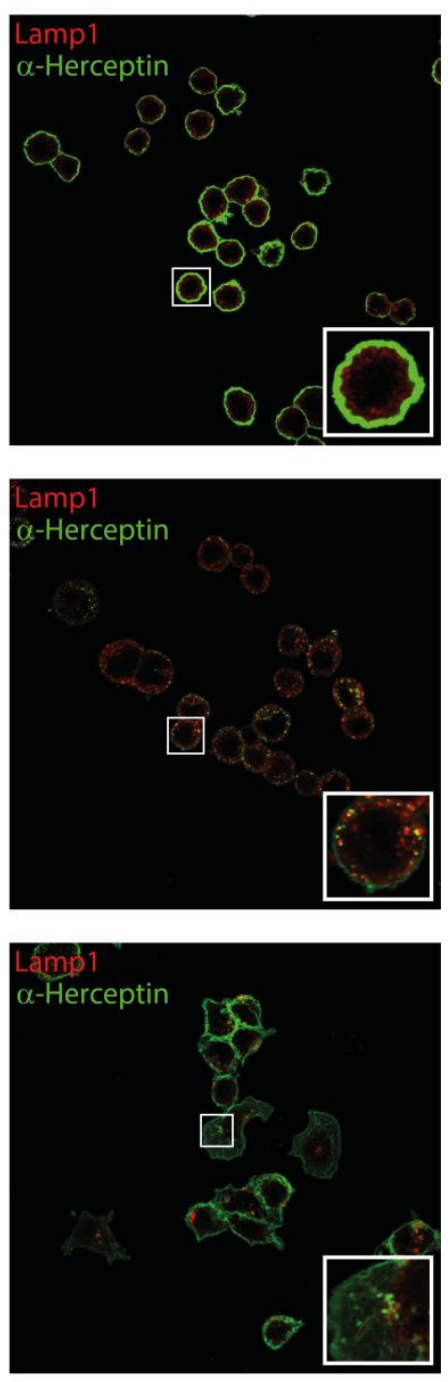

Lamp1

$\alpha$-Herceptin
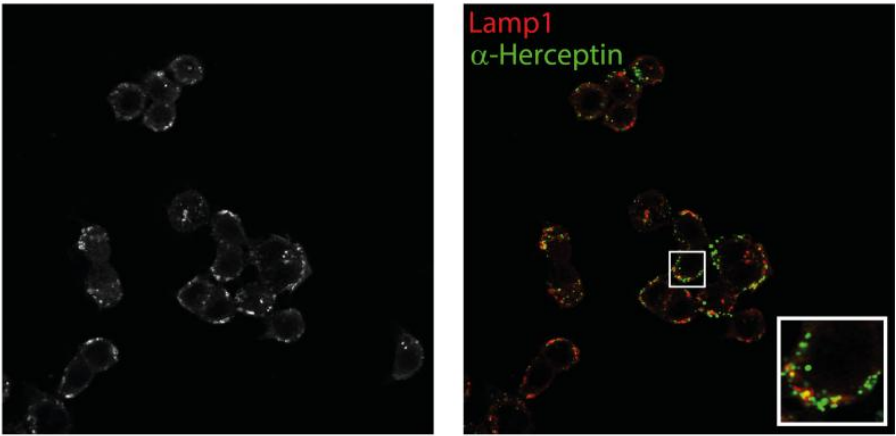
Figure 4
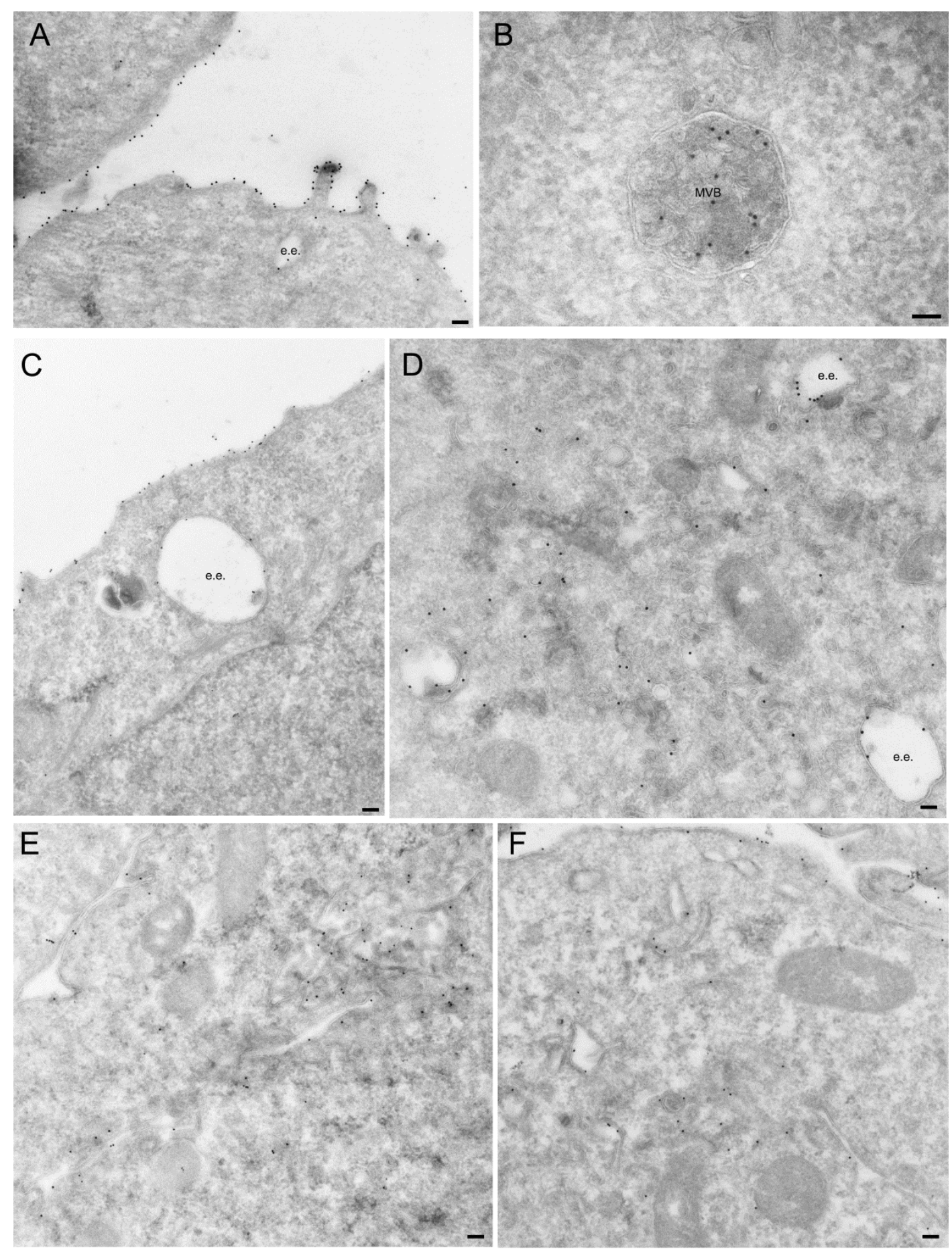
Figure 5

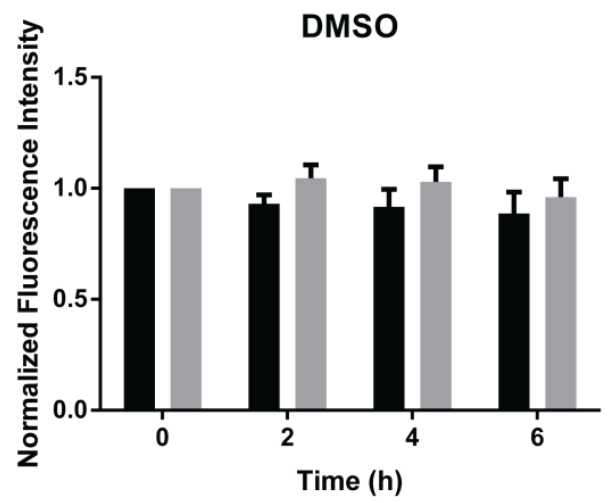

- NT SiRNA

- CHC siRNA

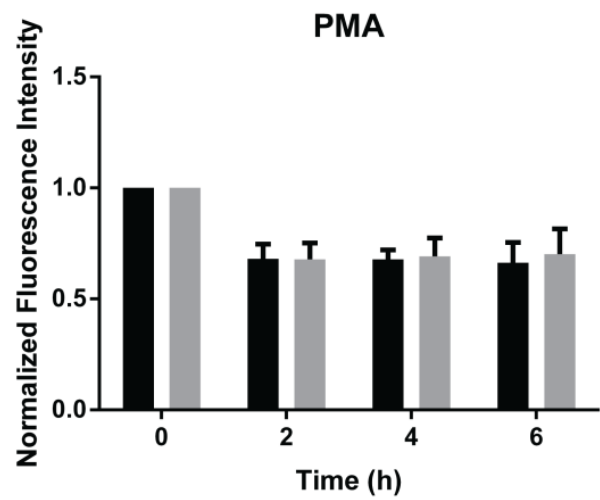

- NT siRNA

- CHC siRNA

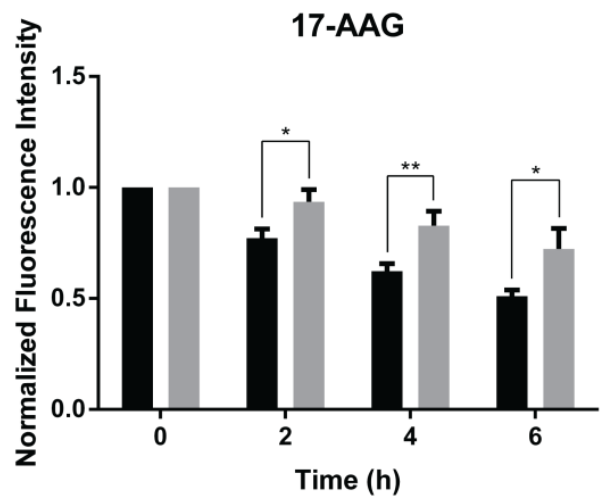

- NT SiRNA

- CHC siRNA

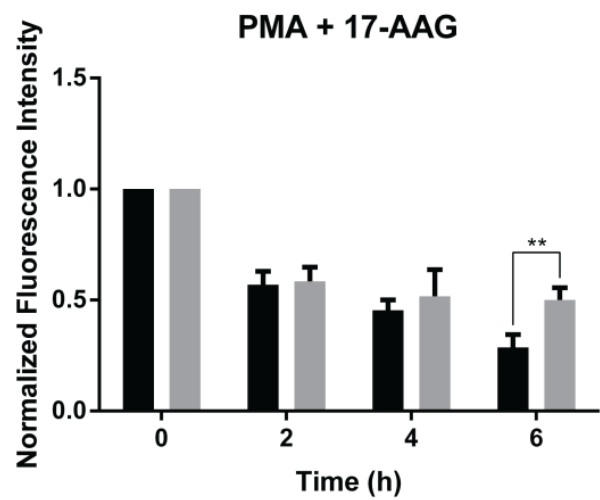

- NT siRNA

- CHC siRNA 
Figure 6

A

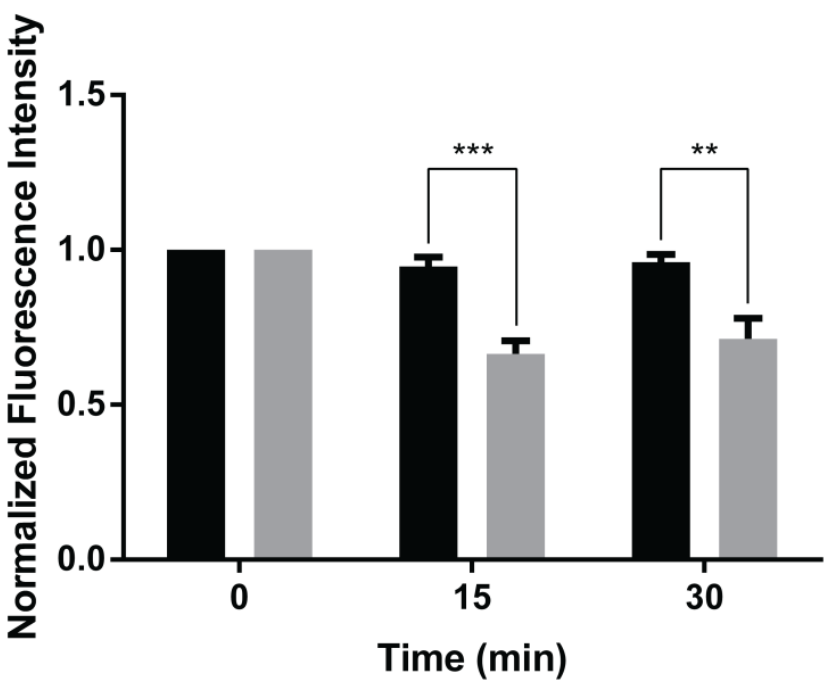

B

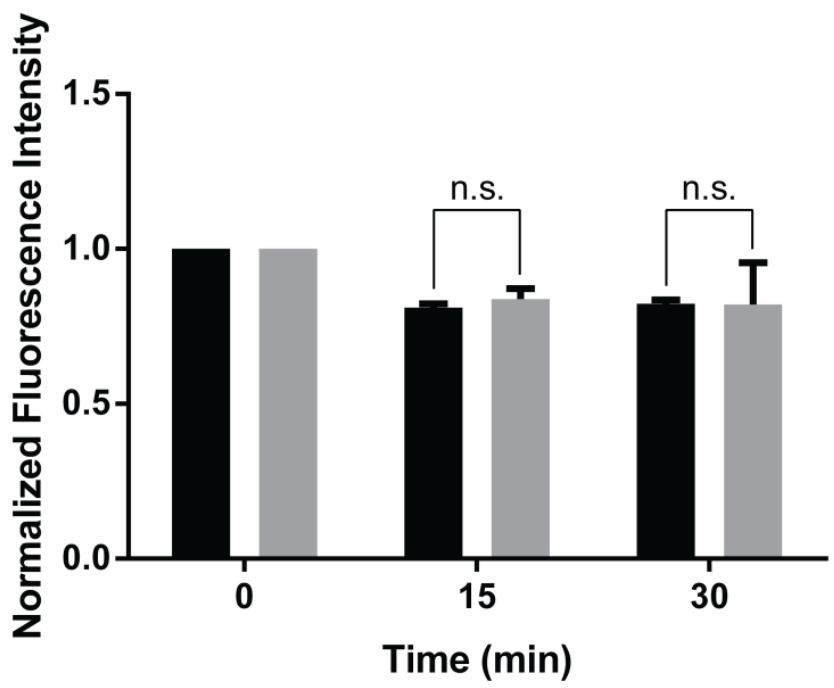

- $\mathrm{M} \beta \mathrm{CD}+\mathrm{DMSO}$

- M $\beta C D+P M A$

Time (min) 
Figure 7

A

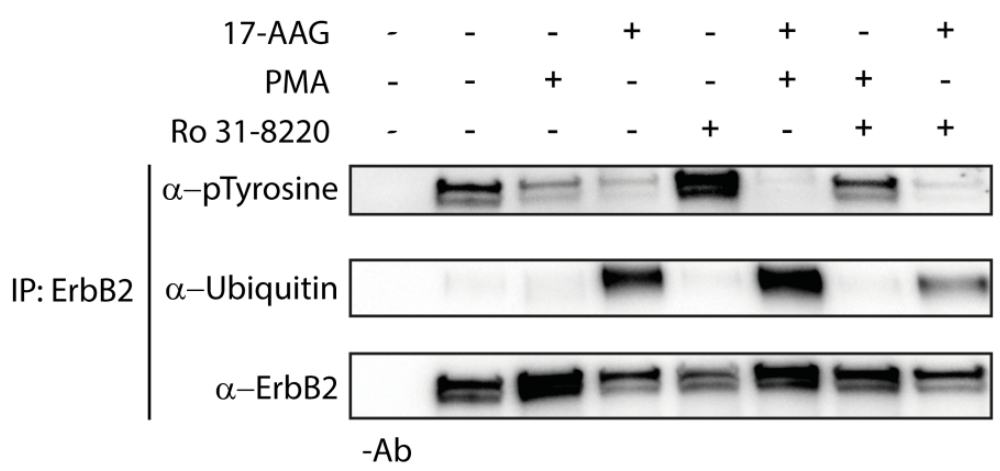

B
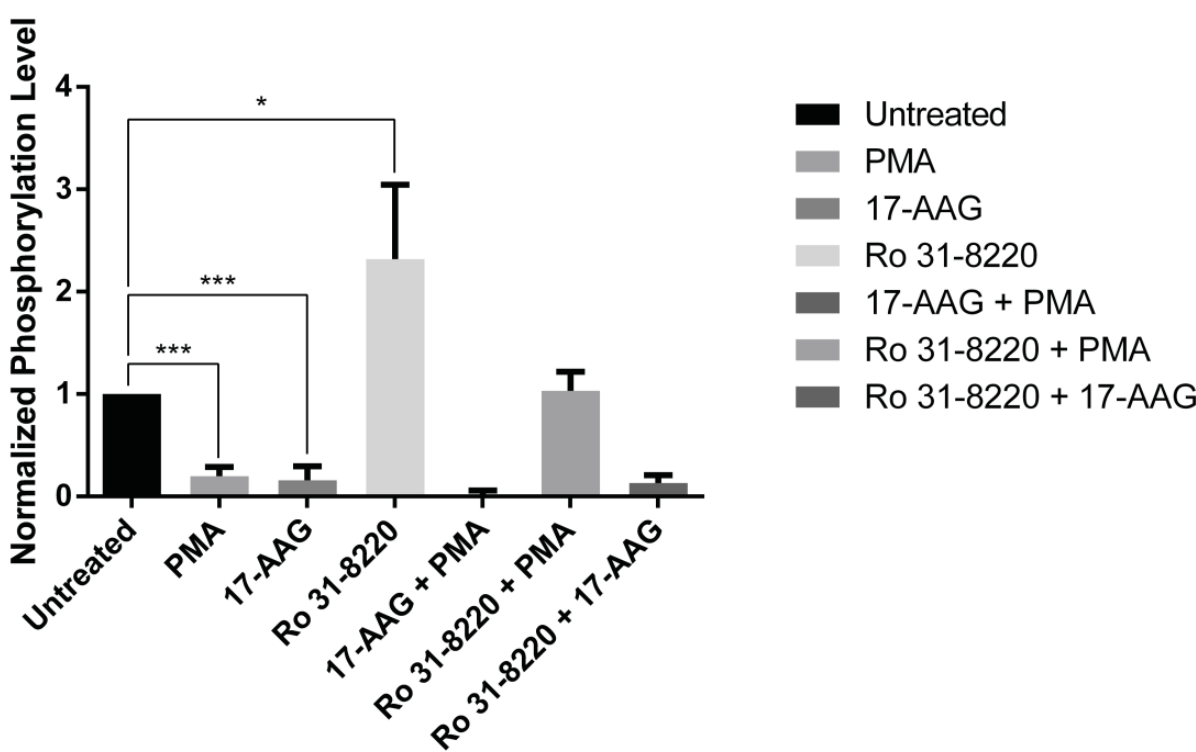

C

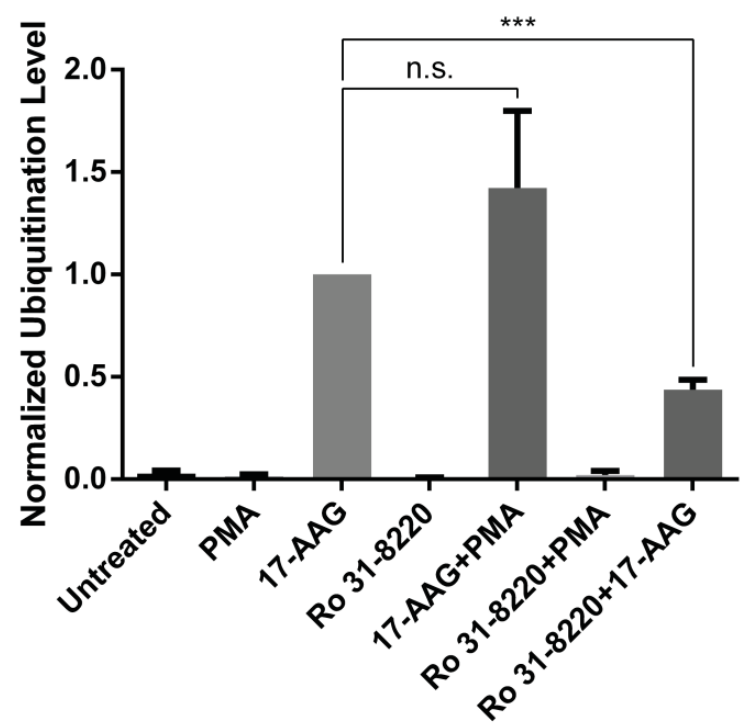

Untreated

PMA

17-AAG

Ro 31-8220

- 17-AAG+PMA

- Ro 31-8220+PMA

- Ro 31-8220+17-AAG 
Figure 8

A
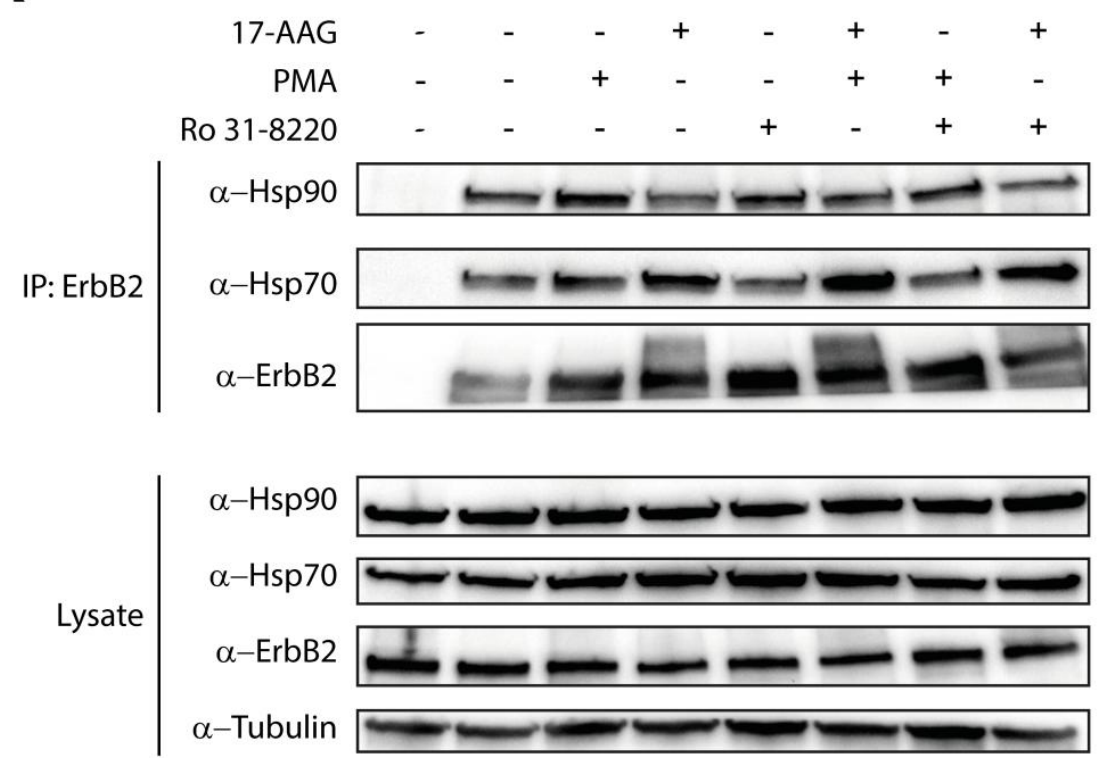

$-A b$

B

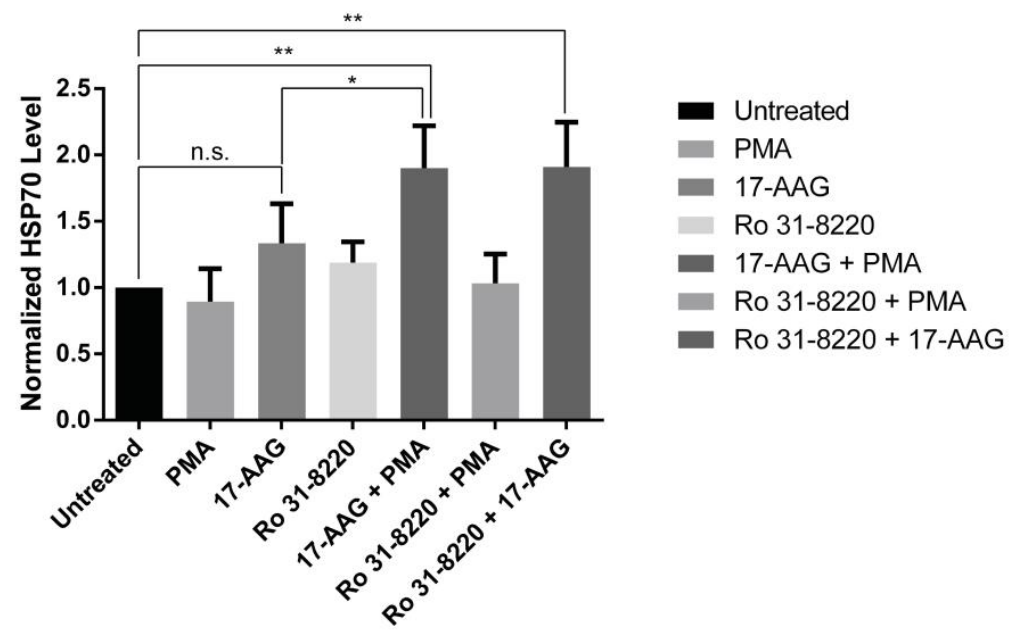

C

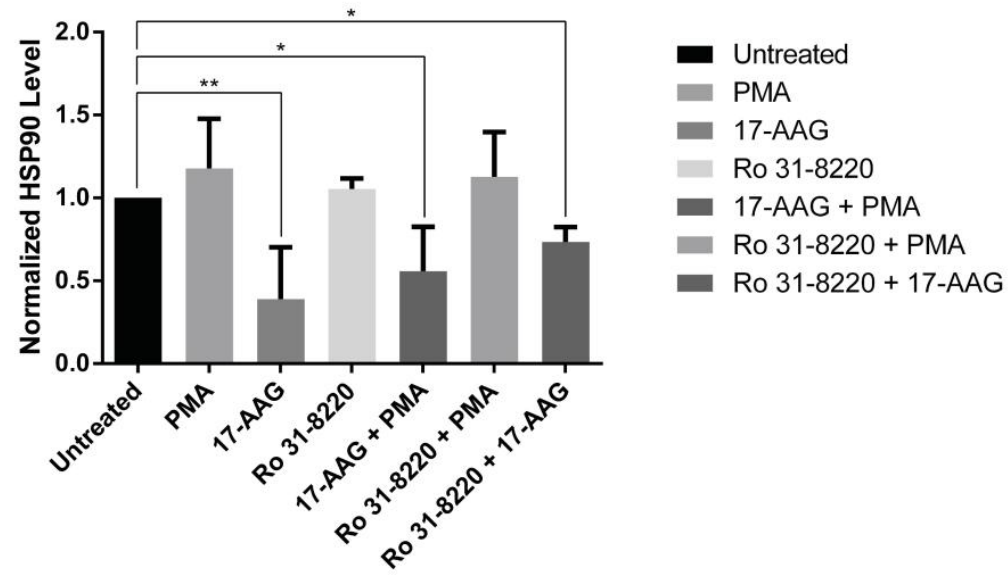



Supplementary material for online publication only
Click here to download Supplementary material for Click here to download Supplementary material for online publication only: Supplementary Figures.pdf 